\title{
LA SINIESTRALIDAD LABORAL EN LA POBLACIÓN INMIGRANTE DE NAVARRA EN EL 2006. UNA APROXIMACIÓN A SUS CAUSAS
}

\author{
ÁNGEL PARRA OSÉS*, VEGA GARCÍA LÓPEZ**, \\ JESÚS FERNÁNDEZ BARAIBAR ${ }^{* * *}$, JOSÉ RAMÓN AYESTARÁN RUIZ BAZÁN****
}

(*) Director de Servicio de Salud Laboral e Investigación. Instituto Navarro de Salud Laboral (INSL)

(**) Jefa de la Sección de Epidemiología Laboral, Investigación y Evaluación Sanitaria. Instituto Navarro de Salud Laboral (INSL)

(***) Jefe de la Sección de Valoración Clínico Laboral e Incapacidades. Instituto Navarro de Salud Laboral (INSL)

(****) Director Gerente de la Fundación Hospital Calahorra.

\section{RESUMEN}

Introducción: El cambio económico y social que está experimentando Navarra en las últimas décadas está asociado con la llegada de un flujo creciente de inmigrantes. El fenómeno migratorio plantea un gran número de desafíos: legislativos, políticos, culturales, sociales, sanitarios y por supuesto laborales. Desde el punto de vista laboral la incorporación de inmigrantes al mercado de trabajo ha supuesto, sin duda, aspectos positivos, pero también algunas disfunciones y problemas, siendo uno de ellos los altos niveles de siniestralidad que presenta este colectivo.

Objetivos: Analizar y profundizar en las características y causas de la siniestralidad en este colectivo y los factores que podrían incidir en ella.

Metodología: Estudio descriptivo - observacional tomando como base los datos del Registro de Accidentes de Trabajo del año 2006.

Resultados: Para un 9,8\% de trabajadores extranjeros, éstos sufren el $20 \%$ de los accidentes de trabajo(AT). Las mujeres extranjeras se accidentan casi 4 puntos menos en porcentaje relativo que las nacionales. La distribución de AT es similar en ambas poblaciones atendiendo a su gravedad, los trabajadores extranjeros sufrieron el 19,3\% de los accidentes graves y el $15,8 \%$ de los mortales .En este colectivo los grupos de edades más jóvenes presentan porcentajes más elevados de siniestralidad. Por sectores económicos: una tercera parte de los accidentes en Agricultura y Construcción corresponden a trabajadores emigrantes. Su distribución porcentual es reflejo de la diferente ocupación sectorial de este colectivo, duplicando los porcentajes en los sectores agrícola y construcción en comparación con la población de acogida. En población extranjera la proporción de hombres que se accidentan es superior al de las mujeres en todos los sectores productivos, excepto en Servicios. Cerca de $80 \%$ de accidentes en población inmigrante acontece en puestos de baja cualificación o no cualificados y casi las tres cuartas partes de los sucesos se producen en trabajadores inmigrantes con menos de un año de antigüedad en el puesto. La forma de producción, descripción y localización de las lesiones y el agente material responsable presentan perfiles de distribución superponibles en ambos colectivos. En porcentaje relativo los accidentes de trabajo notificados por Empresas de Trabajo Temporal en inmigrantes superan a los comunicados en población autóctona y mientras que casi el $75 \%$ se dan en varones, una tercera parte corresponden a población trabajadora extranjera. Además mientras el peso relativo de los ocurridos en mujeres extranjeras con esta modalidad de contrato supera al de nativas, en varones ocurre al contrario.

Los índices de incidencia de AT por sector de actividad son superiores en el colectivo extranjero frente a los índices en población total, incluso en aquellas actividades menos representadas. En población inmigrante tanto los índices de incidencia globales como los diferentes índices según gravedad se duplican con respecto a la población nacional .Estos índices son inferiores en los países UE en relación al resto de países no UE .Por zonas geográficas de ori- 
gen superan el índice medio los trabajadores del Magreb, Europa Occidental y África y por países Marruecos, Argelia y Portugal.

Conclusiones y discusión: Tal vez las condiciones de trabajo que se caracterizan por la excesiva temporalidad, la frecuente subcontratación, el elevado índice de rotación (casi las tres cuartas partes de los accidentados extranjeros llevaban menos de un año en el puesto de trabajo) hacen que proporcionalmente el número de extranjeros con escasa experiencia y falta de adaptación sea todavía mayor que en el conjunto de la población. Es posible que la inestabilidad y precariedad laboral que afectan al colectivo inmigrante pudieran influir en su mayor incidencia. Otros trabajos a nivel nacional e internacional confirman tal aumento en los índices de incidencia. Analizar si este exceso de accidentalidad se debe a factores ocupacionales, tareas de mayor riesgo o bien es debida a factores de índole cultural, idiomática o adaptativos (tiempo de permanencia en nuestro país)son factores que se abordan en la discusión.

\section{SUMMARY}

Introducction: The economical and social changes Navarra is suffering during the last decades, is connected with the increasing immigration income rates. This aspect supposes different and huge legal, political, cultural, social, sanitary and of course professional challenges. Professionally speaking the big immigration income rates have, of course, advantages but have also some problems and dysfunctions as the very high accident levels this collective is suffering.

Objetives: Analyzing and widening the accident's characteristics and reasons and studying the possible causes

Methodology: Descriptive and observation study by analyzing the Working Accident Register Year 2006.

Results: At the moment a 9,8\% of the total workers are foreign workers. These foreign workers have a $20 \%$ of the total working accident rate (WAR). Foreign working women have $4 \%$ less of the WAR than the local working women .If we talk about the seriousness of the accidents; the WAR average is similar between the foreign and the local workers. Foreign workers suffer the $19,3 \%$ of the grave accidents and $15,8 \%$ of the fatal ones .The under-aged working groups have a higher $\%$ of working accidents. If we study the different economical sectors, the results are the following: One-third of the accidents occurred in the Agriculture and Construction sector are suffered by immigrant workers. The reason is that immigrant workers cover a very wide range of sectors, being double as local workers in these both mentioned sectors. Immigrant men workers accident rate is higher than the immigrant women workers accident rate in all the sectors, except the non-productive industries. Almost the $80 \%$ of the working accidents suffered by the immigrant population occurred in the low level or not level qualification jobs and almost three quarters of the casualties are less than one year experimented workers. The accident's happenings are, for both profiles, similar.The relative percent of the working accidents disclosed by the Casual Job Search Companies is higher for the immigrant population as for the local one. Almost the $75 \%$ is suffered by men workers and one-third by foreign workers. The relative percent of the working accidents disclosed by the Casual Job Search Companies is also higher for the foreign working women but lower for foreign working men. The incidence rate classified by activity sector is always higher for the foreign collective, even the less represented activity sectors. The immigrant population's accident rate is double not only for the global rate but also for all the other rates classified by seriousness. These rates are lower for the EU countries as for the NO-EU countries. The highest rates are found in the following areas: Maghreb, Occidental Europe and Africa. The countries classification is the following: Morocco, Algeria and Portugal.

Conclusion and discussions: Perhaps the too temporal working conditions or the too frequent subcontracting working conditions or the too frequent rotary conditions connote a higher rate of non-experience or non-adapted immigrant workers .Perhaps this inconstancy or this predicament acts on the working accident rate. Other national and international works corroborate the accident rate increase. The search of the accident rate's source: working or risk factors or cultural, idiomatic or adaption factors will be under discussion.

\section{KEY WORDS}

Occupational injuries, immigrants workers ,characteristics and causes. 


\section{INTRODUCCIÓN}

En los últimos años la sociedad del trabajo esta sufriendo cambios sociológicos y demográficos de influencia decisiva. El creciente envejecimiento de la población laboral, la decidida incorporación de la mujer al mercado laboral y el nuevo perfil de la población activa donde destaca el fenómeno de la emigración son algunos de ellos.

El proceso de cambio económico y social que está experimentando Navarra en las últimas décadas está asociado con la llegada de un flujo de inmigrantes creciente a partir del nuevo siglo. El fenómeno migratorio plantea un gran número de desafíos: legislativos, políticos, culturales, sociales, sanitarios y por supuesto laborales. Desde el punto de vista del mercado de trabajo su influencia ha sido decisiva como factor de cambio económico en términos de crecimiento de producción y demanda interna.

Además de su impacto en el crecimiento demográfico ${ }^{1}$, su presencia en el mercado de trabajo ha supuesto efectos positivos. En Navarra que cuenta con casi 600.000 habitantes, el $8,41 \%$ son inmigrantes, aportando el 1,3\% al conjunto del estado. El colectivo de extranjeros supone casi el 10\% de la población activa y su presencia en algunos sectores productivos es decisiva para la viabilidad de los mismos. Su incorporación ha supuesto un impulso a la actividad, un rejuvenecimiento generacional de la población activa y un aumento en las tasas de ocupación. Han cubierto los puestos de trabajo que han dejado los desplazamientos sectoriales de la mano de obra autóctona y han facilitado la incorporación de la mujer al mercado laboral. Pero, no cabe duda de que su llegada también ha supuesto algunas disfunciones y problemas. La situación laboral de los extranjeros en Navarra presenta dificultades de inserción, la tasa de paro duplica a la de los autóctonos, afectando sobre todo a mujeres y jóvenes, aunque el paro de larga duración afecta menos a este colectivo. Casi el $45 \%$ de los inmigrantes desempeñan trabajos eventuales, un porcentaje que también es elevado en la población autóctona $(29 \%)^{2}$. Además cuatro de cada diez podrían encontrarse en situación irregular y España es el país con más extranjeros desclasificados, un $42 \%$ no ocupan empleos acordes con su nivel de formación, siendo característica en nuestra comunidad una fuerte espe- cialización productiva en función de sus orígenes ${ }^{3}$. Además sufren altos niveles de siniestralidad lo que conlleva sufrimiento personal y un alto coste económico y social.

Así pues, si a este perfil laboral añadimos las dificultades de adaptación por barreras idiomáticas, diferentes valores y pautas culturales, falta de apoyo social y aislamiento, completamos el círculo que define a este grupo como especialmente vulnerable. Políticas de empleo, así como de seguridad y salud que tengan en cuenta estas circunstancias son los mejores instrumentos para una integración plena.

\section{OBJETIVOS}

- Aumentar el conocimiento sobre las condiciones de trabajo en relación con la salud laboral y sus determinantes sociodemográficos y sociolaborales en la población extranjera en Navarra

- Analizar y profundizar en las características y las causas de la siniestralidad laboral en este colectivo y los factores que directa o indirectamente podrían incidir en ella.

- Identificar dentro de este subgrupo aquellos perfiles laborales y actividades económicas que presenten mayor riesgo ("puntos críticos").

- Orientar los programas y actuaciones preventivas sobre este colectivo hacia el rendimiento y eficacia en la lucha activa contra la siniestralidad.

- Iniciar nuevas hipótesis y líneas de investigación que nos permitan explicar los factores (ocupacionales, culturales, idiomáticos, adaptativos...) que subyacen en el exceso de siniestralidad de estos trabajadores.

\section{METODOLOGÍA}

Estudio descriptivo-observacional, tomando como base los Sistemas de Información del Instituto Navarro de Salud laboral, en concreto, los datos del registro de Accidentes de Trabajo del año 2006. Se realiza un análisis descriptivo de los accidentes con baja en jornada de trabajo en este subgrupo poblacional en relación a diferentes variables: gravedad, actividad económica-descripción de la lesión, antigüedad en el puesto de trabajo, edad, país de ori- 


\section{J. FERNÁNDEZ BARAIBAR, J. R. AYESTARÁN RUIZ BAZÁN}

gen, parte del cuerpo lesionada, agente material, forma en que se produjeron, ocupación, actividad económica-gravedad, accidentes en empresas de trabajo temporal, índices de incidencia $\left(\mathrm{n}^{\circ}\right.$ de accidentes por mil trabajadores) por sección de actividad y país de origen, introduciendo la perspectiva de género y comparándolos con la población española siempre que sea posible.

\section{RESULTADOS}

Antes de presentar los datos es preciso señalar algunas matizaciones:

- los datos aportados desde el Instituto Navarro de Salud laboral (INSL) hacen referencia a los accidentes con baja laboral en jornada de trabajo, excluyendo los accidentes "in itinere".

- esta información está referida al conjunto de trabajadores extranjeros (procedentes de la UE y extracomunitarios).

- se analiza la siniestralidad laboral desde una perspectiva de regularidad laboral.
La media de trabajadores afiliados en el año 2006 fue 225.013, suponiendo los extranjeros el 9.8\% (22.111 trabajadores).

El primer dato que destaca es que durante el año 2006 en números absolutos se han registrado en la población trabajadora inmigrante $\mathbf{2 5 5 2}$ accidentes con baja en jornada de trabajo (A. T.). Porcentualmente suponen el $\mathbf{2 0 \%}$ de todos los accidentes, ya que el número total de siniestros declarados fue de 12739. En este colectivo, el $99 \%$ de ellos fueron leves (2525), 24 tuvieron la consideración de graves ( 23 de ellos ocurrieron en hombres) y 3 fueron mortales ( 2 de ellos en hombres).

La distribución porcentual de la siniestralidad en el colectivo inmigrante resulta considerablemente desigual entre hombres y mujeres: el $84 \%$ de los AT acontecen en hombres (frente al $80 \%$ en la población masculina nacional) y el $16 \%$ en mujeres (frente al 20\% de los AT en las mujeres nacionales). Las mujeres extranjeras globalmente se accidentan casi 4 puntos menos en porcentaje relativo que las nacionales. (Tabla 1)

\section{ACCIDENTES DE TRABAJO CON BAJA EN JORNADA DE TRABAJO SEGÚN GRAVEDAD POR GÉNERO Y NACIONALIDAD}

NAVARRA 2006

\begin{tabular}{|l|c|c|c|c|c|}
\hline \multirow{2}{*}{ GÉNERO } & \multirow{2}{*}{ Leves } & \multirow{2}{*}{ Graves } & \multirow{2}{*}{ Mortales } & \multicolumn{2}{|c|}{ Extranjeros } \\
\cline { 5 - 6 } & & & & $\mathrm{n}^{0}$ & $\%$ \\
\hline Hombre & 2120 & 23 & 2 & 2145 & $84,1 \%$ \\
Mujer & 405 & 1 & 1 & 407 & $15,9 \%$ \\
Total & 2525 & 24 & 3 & 2552 & $100,0 \%$ \\
\hline
\end{tabular}

\begin{tabular}{|c|r|}
\hline \multicolumn{2}{|c|}{ Españoles } \\
\hline $\mathrm{n}^{0}$ & \multicolumn{1}{|c|}{$\%$} \\
\hline 8174 & $80,2 \%$ \\
2013 & $19,8 \%$ \\
10187 & $100,0 \%$ \\
\hline
\end{tabular}

Tabla 1.

Son varias las causas que probablemente podrían explicar este desequilibrio por género y aunque sería preciso verificarlas es posible señalar algunas de ellas. Por ejemplo, el hecho que los hombres ocupen empleos con mayor riesgo, la mayor incidencia de irregularidad en la población femenina inmigrante, por lo que los posibles accidentes no son declarados o la circunstancia de una mayor proporción de hombres ocupados.
El $n^{\circ}$ total de AT con baja en el 2006 fue 12739 , de los cuales 12596 fueron leves (98,9\%), 124 graves y 19 mortales.

Atendiendo al grado de lesión, el perfil de distribución es similar en ambas poblaciones. Los accidentes sufridos por el colectivo inmigrante: el $99 \%$ son leves, $0,9 \%$ graves y un $0,1 \%$ mortales. Son en números absolutos: 2525 leves, 24 graves (1 en 
agricultura, 10 en industria, 9 en construcción y 4 en servicios) y 3 mortales ( 1 en industria, 1en construcción y 1 en transporte).Es decir, tan solo aportaron el 15,8 \% de mortalidad total. Los accidentes graves en el colectivo de extranjeros representan el $19,3 \%$ de los accidentes totales de esta tipología. (Tabla 2)
Si tenemos en cuenta género y grado, comparando ambas poblaciones, el porcentaje relativo de AT leves y graves en hombres extranjeros superan ligeramente a los ocurridos en hombres autóctonos en ambos tipos de accidentes, siendo éste comparativamente superior igualmente en los AT mortales ocurridos en mujeres extranjeras. (Tablas $\mathbf{3 a} \mathbf{y} \mathbf{3 b}$ )

\begin{tabular}{|l|l|c|c|c|c|c|c|}
\hline \multirow{3}{*}{$\begin{array}{l}\text { EXTRAN- } \\
\text { JEROS }\end{array}$} & GENERO & LEVES & GRAVES & MORTALES & LEVES (\%) & GRAVES (\%) & MORTALES (\%) \\
\cline { 2 - 8 } & HOMBRE & 2.120 & 23 & 2 & 16.8 & 18.5 & 10.5 \\
\cline { 2 - 8 } & MUJER & 405 & 1 & 1 & 3.2 & 0.8 & 5.3 \\
\hline SUBTOTAL & & 2.525 & 24 & 3 & 20 & 19.3 & 15.8 \\
\hline \multirow{2}{*}{ NACIONAL } & HOMBRE & 8.067 & 92 & 15 & 64 & 74.2 & 78.9 \\
\cline { 2 - 8 } & MUJER & 2.004 & 8 & 1 & 16 & 6.5 & 5.3 \\
\hline SUBTOTAL & & 10.071 & 100 & 16 & 80 & 80.7 & 84.2 \\
\hline TOTAL & & 12.596 & 124 & 19 & 100 & 100 & 100 \\
\hline
\end{tabular}

Tabla 2.

\begin{tabular}{|l|c|c|c|c|c|c|c|c|}
\hline GENERO & \multicolumn{9}{|c|}{ GRADO } & TOTALES & $\%$ \\
\hline & LEVES & $\%$ & GRAVES & $\%$ & MORTALES & $\%$ & & \\
\hline HOMBRES & 8.067 & 80.1 & 92 & 92 & 15 & 93.7 & 8.174 & 80.2 \\
\hline MUJERES & 2.004 & 19.9 & 8 & 8 & 1 & 6.3 & 2.013 & 19.8 \\
\hline TOTAL & 10.071 & 100 & 100 & 100 & 16 & 100 & 10.187 & 100 \\
\hline
\end{tabular}

Accidentes de Trabajo según Género y Grado en la población nacional.

Tabla $3 a$.

\begin{tabular}{|l|c|c|c|c|c|c|c|c|}
\hline GENERO & \multicolumn{9}{|c|}{ GRADO } & TOTALES & $\%$ \\
\hline & LEVES & $\%$ & GRAVES & $\%$ & MORTALES & $\%$ & & \\
\hline HOMBRES & 2.120 & 84 & 23 & 95.8 & 2 & 66.6 & 2.145 & 84 \\
\hline MUJERES & 405 & 16 & 1 & 4.2 & 1 & 33.3 & 407 & 16 \\
\hline TOTAL & $\begin{array}{c}2.525 \\
(99 \%)\end{array}$ & 100 & $\begin{array}{c}24 \\
(0,9 \%)\end{array}$ & 100 & $\begin{array}{c}3 \\
(0,1 \%)\end{array}$ & 100 & 2.552 & 100 \\
\hline
\end{tabular}

Accidentes de Trabajo según Género y Grado en la población extranjera.

Tabla $3 b$.

\begin{tabular}{|l|c|c|c|c|c|c|c|c|c|c|c|c|}
\hline GENERO & \multicolumn{4}{|c|}{ POBLACION NACIONAL } & \multicolumn{4}{c|}{ POBLACION EXTRANJERA } & \multicolumn{1}{c|}{ TOTAL } \\
\hline & LEVES & $\mathrm{G}$ & $\mathrm{M}$ & $\mathrm{T}$ & $\%$ & LEVES & $\mathrm{G}$ & $\mathrm{M}$ & $\mathrm{T}$ & $\%$ & \\
\hline HOMBRES & 8.067 & 92 & 15 & 8.174 & 79.2 & 2.120 & 23 & 2 & 2.145 & 20.8 & $10.319(100 \%)$ \\
\hline MUJERES & 2.004 & 8 & 1 & 2.013 & 83.2 & 405 & 1 & 1 & 407 & 16.8 & $2.420(100 \%)$ \\
\hline
\end{tabular}

Tabla 4.

De los 10319 eventos totales ocurridos en hombres, los extranjeros sufrieron el 20,8\% (2145) y de los 2420 accidentes protagonizados por mujeres, las extranjeras sufrieron el 16,8\% (407). (Tabla 4)

AT con baja en jornada de trabajo según nacionalidad por grupos de edad.
En ambos colectivos destaca la mayor accidentalidad en los grupos etarios de 20-29 años y 30-39 años, disminuyendo con la edad. En estos dos intervalos de edad los porcentajes son superiores en la población extranjera (32 versus $28 \%$ ) y (40 versus $29 \%$ ) respectivamente, en comparación con la nacional, mientras que en el resto de grupos de edad éste 


\section{J. FERNÁNDEZ BARAIBAR, J. R. AYESTARÁN RUIZ BAZÁN}

es superior en la población nacional, especialmente en el grupo de 50-59 años, probablemente por el mayor envejecimiento de la población nacional. En el grupo de 20-29 años se dan mayor porcentaje de AT en trabajadores de Europa (Este y Oeste) y Asia y en el grupo de 30-39 años en los nacidos en África, el Magreb y Centro-Sudamérica. (Figura 1)

\section{Análisis por sectores y actividades económicas}

Desagregando la información según sectores y actividades económicas y teniendo en cuenta a su vez la proporción de la accidentalidad de extranjeros sobre el total de la siniestralidad en cada sector se debe destacar que las mayores proporciones se

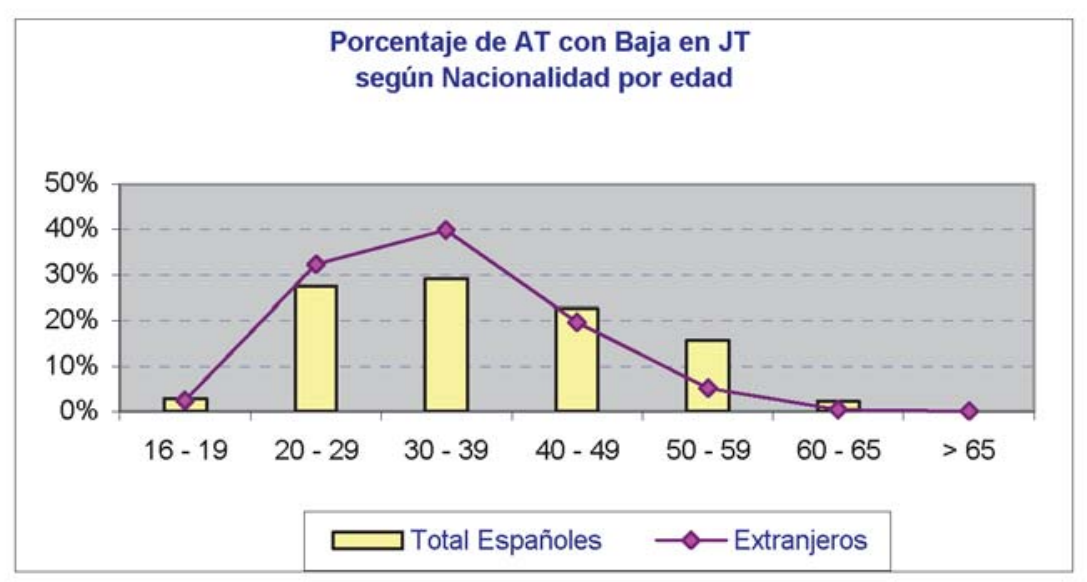

Figura 1

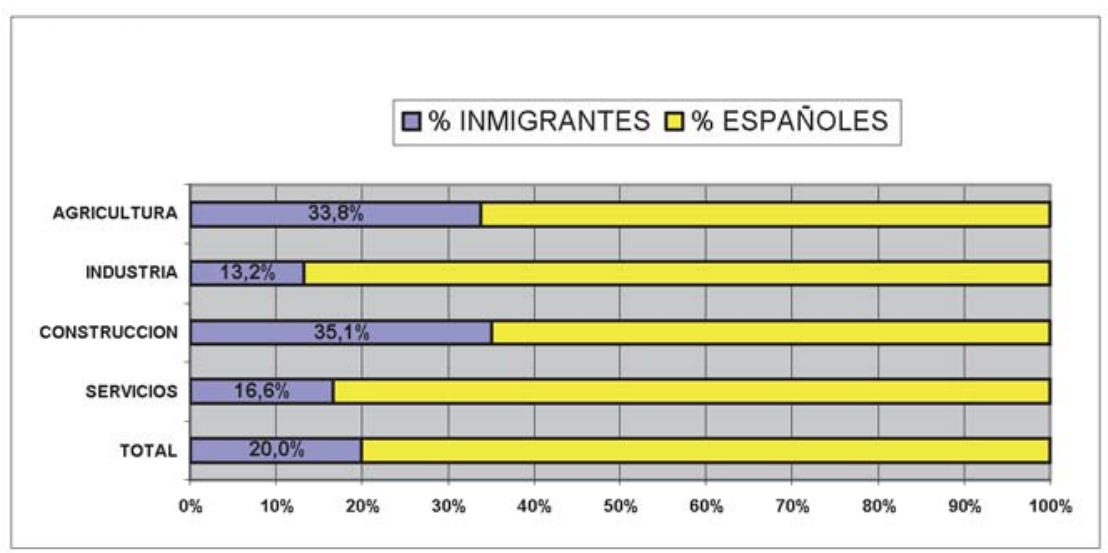

Figura 2

encuentran en el sector agrícola $(33,8 \%)$ y en la construcción (35,1\%). En ambos casos, del total de A.T. en cada uno de estos sectores económicos aproximadamente una tercera parte fueron protagonizados por inmigrantes. De dichos accidentes el 16,6\% se dieron en servicios y el $13,2 \%$ en la industria (Figura 2). Este perfil se reproduce con pequeñas variaciones porcentuales tanto en hombres como en mujeres. Si observamos la siniestralidad total según sexo y sector productivo, el porcentaje relativo de los AT en extranjeras en relación al total de accidentes en mujeres en cada sector económico supera ligeramente al mismo porcentaje de AT en hombres extranjeros en los tres sectores, excepto en construcción. (Figura 3A y 3B) 


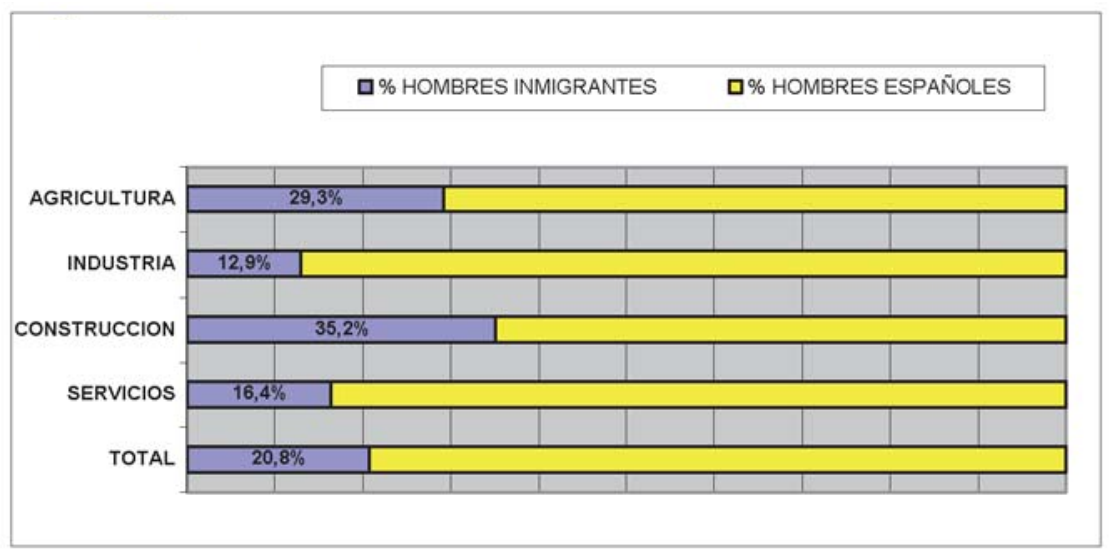

Figura $3 a$.

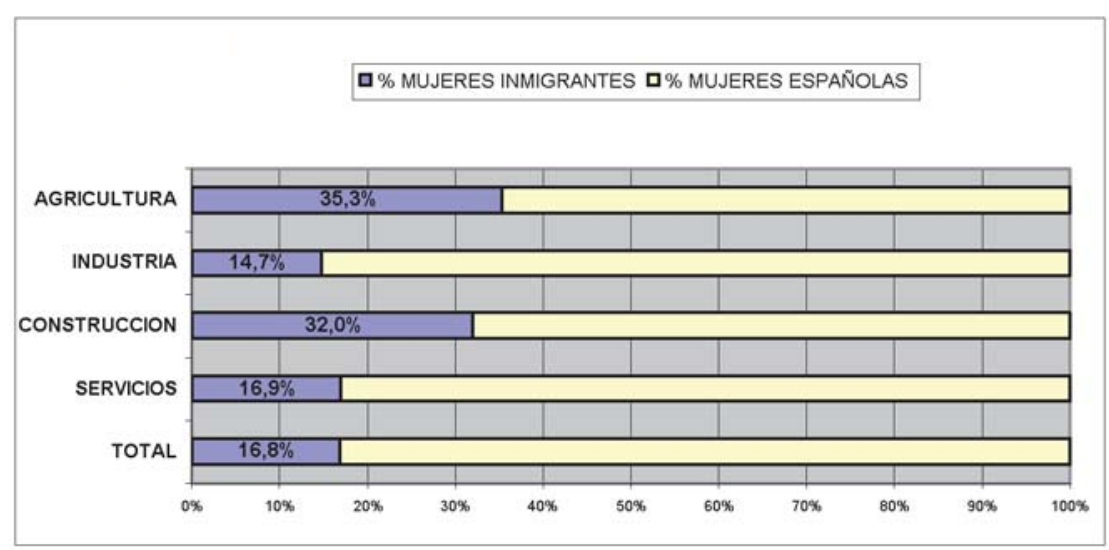

Figura $3 b$.

Teniendo en cuenta, esta vez, la distribución porcentual en población extranjera de los accidentes según sectores económicos se observa como el $40,8 \%$ de los accidentes se producen en la construcción. La siniestralidad en el resto de los sectores es del $26,6 \%$ en Industria, el $27,3 \%$ en el sector servicios y un $5.2 \%$ en el agrícola.

Comparando la distribución de accidentes del colectivo inmigrante y del nacional se aprecia como el porcentaje de la siniestralidad en la población no extranjera es superior en la industria (44\% versus $26,6 \%$ ) y en el sector servicios $(34,5$ versus $27,3 \%)$, mientras que en el colectivo extranjero el porcentaje se duplica en los sectores agrícola $(5,2$ versus $2,6 \%)$ y construcción (40,8 versus $18,9 \%)$ con respecto a la población de acogida. Es preciso tener en cuenta que estos dos sectores son los que ocupan más extranjeros. (Figura 4).

Este mismo perfil se repite comparando en ambas poblaciones los AT según género y sector económico, tanto en hombres como en mujeres, siendo los porcentajes de accidentes en mujeres de ambos colectivos en el sector servicios muy similares. Si comparamos en cada grupo poblacional la distribución porcentual de los AT entre hombres y mujeres en los diferentes sectores podemos observar: valores superiores en hombres frente a mujeres en todos los sectores, excepto en servicios, donde las mujeres se accidentan más en porcentaje relativo que los hombres en ambos colectivos, siendo las diferencias más acusadas en el colectivo extranjero a favor de los AT en hombres frente a mujeres en cons- 


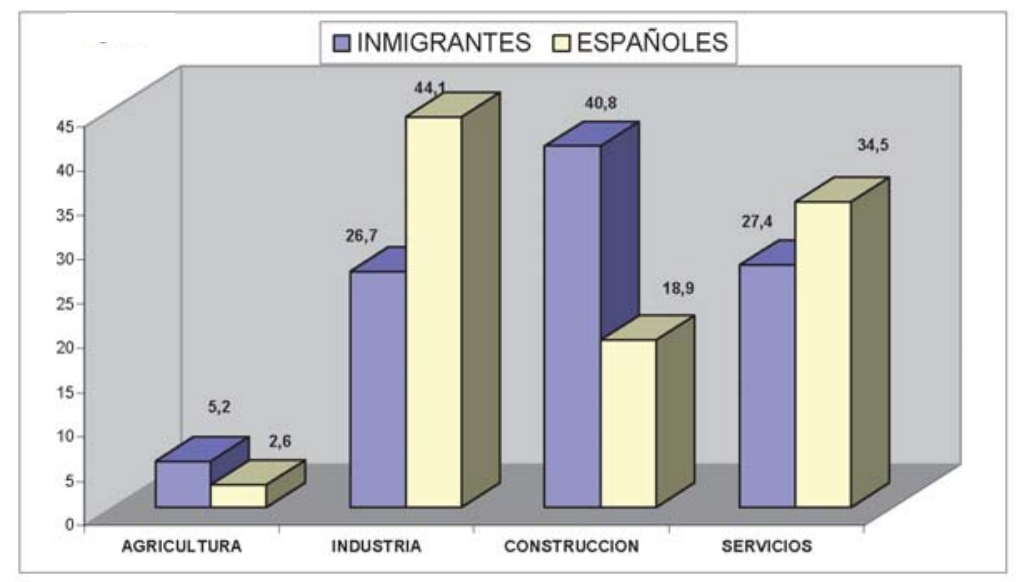

Figura 4

trucción y a favor de las mujeres en relación a los hombres en servicios. (Figuras 5A y 5B).

Dentro del sector industria destacan como actividades, en las que el peso de los accidentes respecto del total de la siniestralidad en extranjeros fue mayor (teniendo en cuenta valores absolutos elevados), la industria de productos alimenticios y bebidas $(7,5 \%)$ y la fabricación de productos metálicos $(4,5 \%)$ y otros minerales no metálicos $(3,6 \%)$. Por su parte, en el sector servicios sobresalen: otras actividades empresariales $(8,2 \%)$, hostelería $(4,8 \%)$, comercio al por menor $(3,1 \%)$ y transporte terrestre $(2,7 \%)$. (Figura 6 )

En hombres destacan: construcción, otras actividades empresariales, industria alimentaria y agricultura y en mujeres: hostelería, otras actividades empresariales, industria de alimentación y comercio al por menor.

Las actividades económicas que produjeron en números absolutos claramente más accidentes en mujeres frente a hombres fueron: hostelería; activi-

\section{DISTRIBUCIÓN PORCENTUAL DE AT POR SECTOR ECONÓMICO, GÉNERO Y NACIONALIDAD}

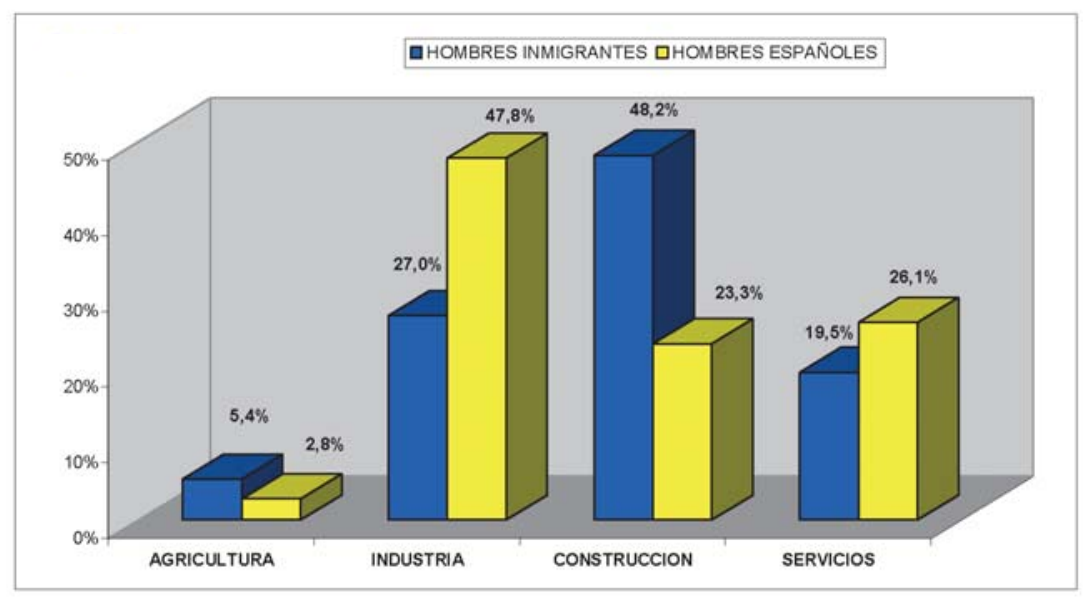

Figura $5 a$ 


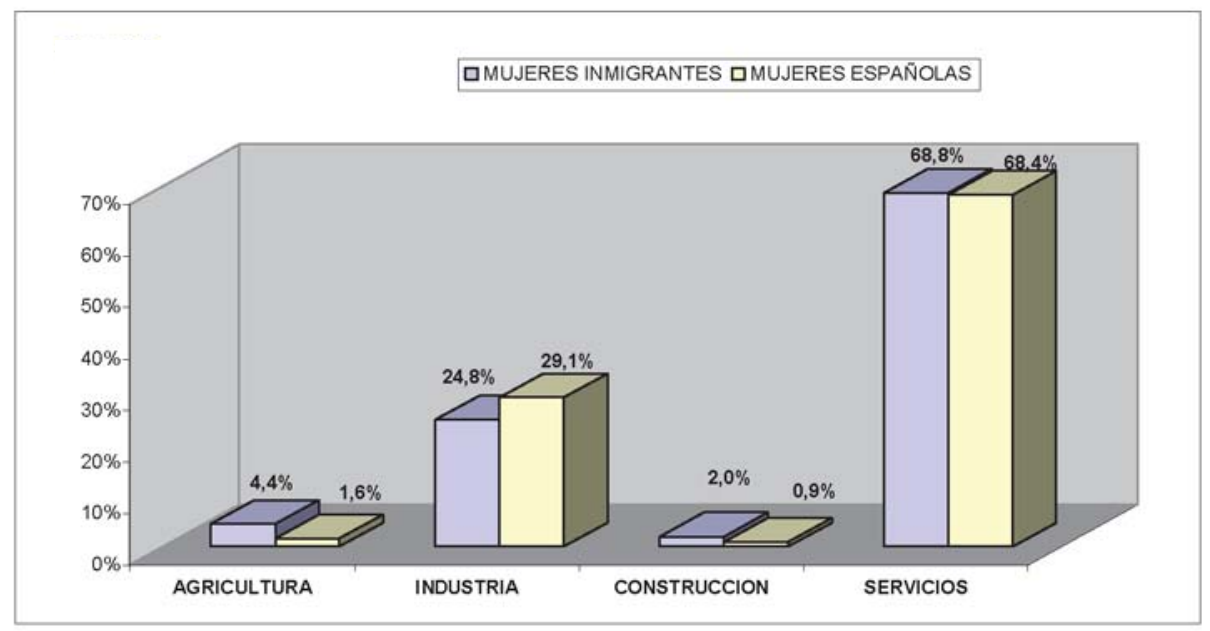

Figura $5 b$

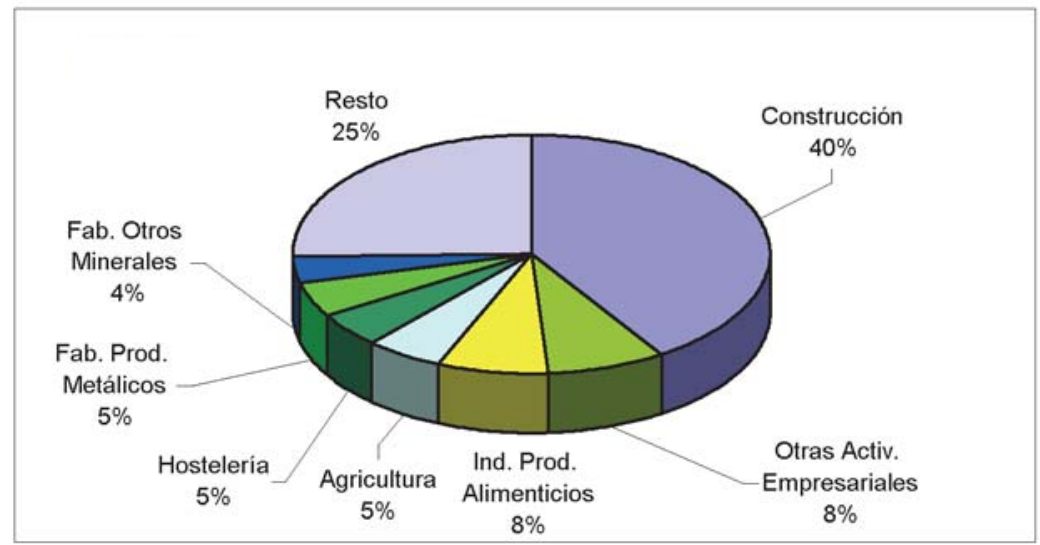

Figura 6

dades sanitarias y veterinarias, servicios sociales y actividades diversas de servicios personales.

Si consideramos el grado de lesión, es preciso señalar que el $41,6 \%$ de los accidentes graves ocurrieron en población extranjera en la industria manufacturera y el $37,5 \%$ de éstos en la construcción.

\section{Accidentes de trabajo y ocupación según nacionalidad}

Cerca del $80 \%$ de los accidentes laborales en la población inmigrante acontecen en puestos de baja cualificación o no cualificados, frente al $62 \%$ en la población trabajadora nacional.
Destacan globalmente y en primer lugar el porcentaje de AT en trabajadores ocupados como "artesanos y trabajadores cualificados", siendo éste superior en población extranjera $(42,4 \%$ versus $34,6 \%$ ), seguido de los AT en "trabajadores no cualificados" que también es superior en dicho colectivo (36,7 versus $25,3 \%$ ); por el contrario los AT en "operadores, instal y maquin. y montadores" (21,8 versus $10,9 \%$ ) y "trabajadores de la restauración, pers.protec, vendedores" (9,5 versus 7,1\%) predominan en población nacional.

Según países de origen, el mayor porcentaje de AT en "trabajadores no cualificados" ocurrieron en aquellos procedentes de Asia, África subsahariana y 


\section{J. FERNÁNDEZ BARAIBAR, J. R. AYESTARÁN RUIZ BAZÁN}

el Magreb, seguidos por los del Europa del Este y Centro-Sudamérica con porcentajes similares.

Los AT en "técnicos, profesionales cientificos e intelectuales" predominan en los norteamericanos. Los "artesanos y trabajadores cualificados" de América del Norte $(66,7 \%)$ y Europa del Oeste
(60,8\%) tienen más AT, siendo la distribución porcentual en el resto de países bastante similar. Los AT en trabajadores de "restauración" predominan en los nacidos en Centro-Sudamérica $(11,3 \%)$ y Asia $(8,7 \%)$, mientras que los AT en "operadores, instal y maquin. y montadores" predominan en Europa del Este (15,4\%). (Tabla 5 y Figura 7 )

\begin{tabular}{|c|c|c|c|}
\hline \multirow{2}{*}{ OCUPACIÓN } & \multicolumn{2}{|c|}{ Extranjeros } & \multirow{2}{*}{$\begin{array}{c}\text { Españoles } \\
\% \\
\end{array}$} \\
\hline & n. ${ }^{\circ}$ & $\%$ & \\
\hline Artesanos y tr. cualificados & 1081 & 42,4 & 34,6 \\
\hline Trabajadores no cualificados & 937 & 36,7 & 25,3 \\
\hline Oper.instal. y maquin. y montad & 277 & 10,9 & 21,8 \\
\hline Tr.Restaurac,pers.protec.vended & 181 & 7,1 & 9,5 \\
\hline Tr.cualif. Agricultura y pesca & 36 & 1,4 & 2,3 \\
\hline Técnicos y profesion. de apoyo & 18 & 0,7 & 2,9 \\
\hline Empleados de tipo Administrat & 10 & 0,4 & 1,8 \\
\hline Técnicos y Prof. Cient. e Intel & 8 & 0,3 & 1,2 \\
\hline Dirección empresas y Admón Publ & 3 & 0,1 & 0,3 \\
\hline Fuerzas armadas & 1 & 0,0 & 0,4 \\
\hline TOTAL & 2552 & 100 & 100,0 \\
\hline
\end{tabular}

Datos provisionales a 22/2/2007

Tabla 5

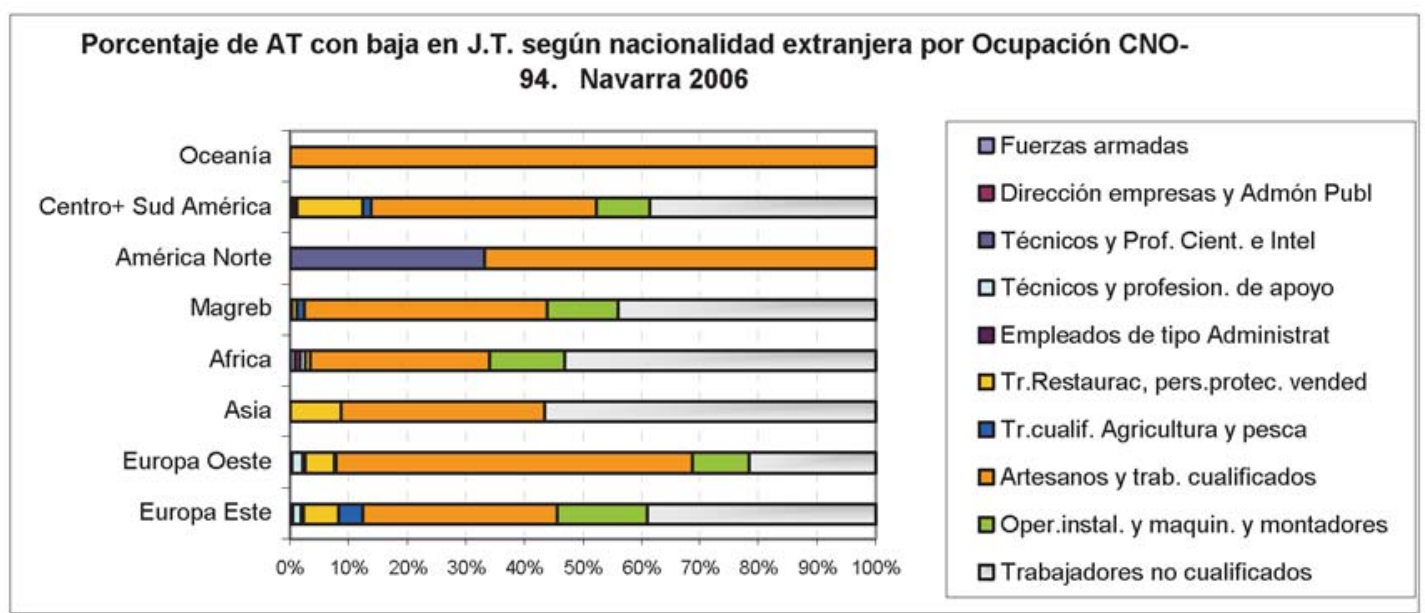

Figura 7 


\section{Accidentalidad y antigüedad}

Por antigüedad, en el colectivo extranjero se produjeron el $37,4 \%$ de los accidentes en trabajadores con menos de 3 meses de antigüedad en el puesto (frente al $18,8 \%$ de los AT en los nacionales) y el $73,2 \%$ en trabajadores con una antigüedad menor del año (frente al $48 \%$ en los nacionales). Los trabajadores de origen nacional con una antigüedad superior a 36 meses sufrieron el $44,4 \%$ de los accidentes (frente al $12.8 \%$ en los inmigrantes de igual permanencia en el puesto).

$\mathrm{Si}$ en el colectivo extranjero introducimos la variable género, observamos que los hombres con una antigüedad menor de un año sufren el $67,3 \%$ de los AT (el 36,7\% los de menos de 3 meses) y las mujeres con una antigüedad menor de un año padecen el $62,6 \%$ (el 41,3\% las de menos de 3 meses) de los accidentes totales de sus respectivos grupos de permanencia en el puesto.

Teniendo en cuenta el grado, los trabajadores extranjeros del subgrupo menos de 3 meses han sufrido sobre el total de accidentes de cada tipología: un $37,5 \%$ de leves $(30,9 \%$ hombres y $6,6 \%$ mujeres), un $33,3 \%$ de graves y un 33,3 de mortales. El subgrupo de menos de un año: un $66,5 \%$ de leves (56,5\% hombres y $10 \%$ mujeres), un $75 \%$ de graves (70,8\% hombres y $4,2 \%$ mujeres) y un $33,3 \%$ de mortales (todos en mujeres), ocurriendo el resto de sucesos en trabajadores con permanencia en el puesto superior a un año. (Tablas 6 y 7)

\section{ACCIDENTES DE TRABAJO CON BAJA EN JORNADA DE TRABAJO SEGÚN NACIONALIDAD POR ANTIGÜEDAD EN EL PUESTO DE TRABAJO}

\begin{tabular}{|c|c|c|c|}
\hline \multicolumn{4}{|c|}{ NAVARRA 2006} \\
\hline \multirow{2}{*}{ Antigüedad Puesto $\mathrm{T}^{\circ}$} & \multicolumn{2}{|c|}{ Extranjeros } & \multirow{2}{*}{$\begin{array}{c}\text { Españoles } \\
\%\end{array}$} \\
\hline & $n .^{\circ}$ & $\%$ & \\
\hline$<3$ meses & 955 & $37,4 \%$ & $18,8 \%$ \\
\hline 4-6 meses & 526 & $20,6 \%$ & $19,3 \%$ \\
\hline 7-12 meses & 387 & $15,2 \%$ & $9,9 \%$ \\
\hline $12-36$ meses & 357 & $14,0 \%$ & $7,5 \%$ \\
\hline$>36$ meses & 327 & $12,8 \%$ & $44,4 \%$ \\
\hline Total & 2552 & $100,0 \%$ & $100,0 \%$ \\
\hline
\end{tabular}

Tabla 6

Forma, parte del cuerpo lesionada, descripción de la lesión y agente material

$\mathrm{Si}$ analizamos la forma en que se produjeron destacan: "sobreesfuerzo físico, trauma psíquico, exposición a radiaciones, ruido, luz" (29,4\%); "choque o golpe contra un objeto en movimiento, colisión" $(24,1 \%)$; "aplastamiento sobre o contra un objeto inmóvil" (18,7\%); "contacto con agente material cortante, punzante, duro, rugoso" $(16,2 \%)$, con una distribución prácticamente superponible a la forma de los accidentes en españoles.
Parte del cuerpo lesionada: en más de un tercio de los AT la parte del cuerpo lesionada fueron las extremidades superiores, seguido por las inferiores $(25,3 \%)$ y espalda incluida la columna dorso-lumbar $(19,7 \%)$. En más del $80 \%$ de los accidentes las lesiones se localizaron en alguna de estas tres partes, con un perfil casi similar en ambos colectivos.

Descripción de la lesión: las dos lesiones más frecuentes en extranjeros son: heridas y lesiones superficiales y dislocaciones, esguinces y torceduras; siendo ligeramente superior en los AT del 


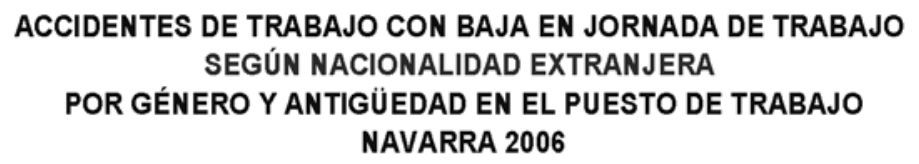

HOMBRES
\begin{tabular}{|l|r|r|c|c|}
\hline Antigüedad Puesto To & \multicolumn{1}{c|}{ Leves } & Graves & Mortales & Total \\
\hline$<3$ meses & 780 & 7 & & 787 \\
$4-6$ meses & 311 & 4 & & 315 \\
$7-12$ meses & 336 & 6 & & 342 \\
$13-36$ meses & 427 & 4 & & 431 \\
$>36$ meses & 266 & 2 & 2 & 270 \\
TOTAL & 2120 & 23 & 2 & 2145 \\
\hline
\end{tabular}

MUJERES
\begin{tabular}{|l|r|c|c|c|}
\hline Antigüedad Puesto To & \multicolumn{1}{|c|}{ Leves } & Graves & Mortales & Total \\
\hline$<3$ meses & 166 & 1 & 1 & 168 \\
$4-6$ meses & 42 & & & 42 \\
$7-12$ meses & 45 & & & 45 \\
$13-36$ meses & 95 & & & 95 \\
$>36$ meses & 57 & & & 57 \\
TOTAL & 405 & 1 & 1 & 407 \\
\hline
\end{tabular}

Tabla 7

colectivo inmigrante la primera (51,7 versus $45,4 \%)$, mientras que la segunda es superior en los AT del grupo nacional (39,1 versus 33,8\%). En tercer lugar figura fracturas de huesos, con ligero predominio en los AT en nacionales (7,5 versus 6,5\%). El conjunto de las tres lesiones representa el $92 \%$ del total en ambos subgrupos.

En todas las actividades económicas los tres tipos de lesiones ocupan el mismo orden, excepto en fabricación de productos metálicos, fabricación de otros minerales no metálicos y otras actividades empresariales que el tercer lugar lo ocupa conmociones y lesiones internas y comercio al por mayor y hostelería, donde el tercer puesto está ocupado por quemaduras, escaldaduras y congelación, siendo desplazada fracturas de huesos a la cuarta posición.

Analizando el agente material se observa que agente implicado con mayor frecuencia es materiales, objetos, productos (en un 32,7\%); seguido en un $13,6 \%$ por edificios, superficies al mismo nivel y en un $9,5 \%$ herramientas manuales sin motor, con un perfil similar en ambas poblaciones. Los AT en los que se hayan involucrados máquinas fijas o móviles suponen cerca del $10 \%$ en ambos colectivos.

\section{Accidentes de trabajo comunicados por ETT.}

Los accidentes notificados por ETT suponen el $4,9 \%$ del total de AT en inmigrantes, mientras que en población nacional los declarados por ETT suponen el $3,1 \%$ del total de accidentes ocurridos en este grupo. (Tabla 8)

De un total de 440 AT con baja notificados por ETT, casi las tres cuartas partes fueron protagonizados por varones (323 sucesos) y 124 corresponden a población trabajadora extranjera $(28,2 \%)$.

Por género, el peso relativo de los AT ocurridos en mujeres extranjeras con esta modalidad de contrato es superior al peso relativo de los AT sufridos por trabajadoras de origen nacional $(31,5 \%$ versus $24,7 \%$ ), en hombres ocurre al contrario. 


\section{ACCIDENTES DE TRABAJO CON BAJA EN JORNADA DE TRABAJO SEGÚN EMPRESA CONTRATANTE POR NACIONALIDAD}

NAVARRA 2006

\begin{tabular}{|l|cr|rr|rr|}
\hline NACIONALIDAD & \multicolumn{2}{|c|}{$\begin{array}{c}\text { Contratados } \\
\text { porETT'S }\end{array}$} & \multicolumn{2}{|c|}{$\begin{array}{c}\text { Contratados por } \\
\text { otras empresas }\end{array}$} & \multicolumn{2}{|c|}{ TOTAL } \\
\hline Español & 316 & $3,1 \%$ & 9871 & $96,9 \%$ & 10187 & $100,0 \%$ \\
Inmigrante & 124 & $4,9 \%$ & 2428 & $95,1 \%$ & 2552 & $100,0 \%$ \\
TOTAL & 440 & $3,5 \%$ & 12299 & $96,5 \%$ & 12739 & $100,0 \%$ \\
\hline
\end{tabular}

Tabla 8

La población inmigrante aporta el $26,3 \%$ de los accidentes en hombres y el 33,3\% de los accidentes en mujeres sobre el total de accidentes ocurridos en cada subgrupo de hombres o mujeres contratados por una ETT. (Tablas 9A y 9B).

Según sector, un $73,4 \%$ de estos eventos ocurrieron en Industria y un $21 \%$ en el sector Servicios. En Industria y Construcción existe un claro y lógico predominio de AT en varones, en el sector Servicios predominan en mujeres y en agricultura se reparten al 50\%. Las actividades económicas que más aportan en números absolutos son: industria de alimentación, fabricación de productos metálicos y fabricación de otros minerales no metálicos.
Distribución ocupacional e índices de incidencia.

Es fundamental a la hora de interpretar estos datos conocer la diferente distribución laboral por sectores productivos del colectivo de extranjeros en relación a la población total. Los sectores de mayor inserción de la población extranjera son Servicios (42\%) y Construcción (28\%), siendo el $17 \%$ en Industria y el 13\% en Agricultura. Esta distribución es bastante diferente a como se distribuye la población total: en Servicios un 55\%, en Industria un $30 \%$, y en Construcción y Agricultura un $10 \%$ y 5\% respectivamente. (Figura 8).

\section{A.T. EN ETT'S SEGÚN GÉNERO Y NACIONALIDAD \% VERTICAL}

\begin{tabular}{|l|c|c|c|c|c|c|}
\hline \multicolumn{1}{|c|}{ Género } & \multicolumn{1}{|c|}{$\%$} \\
\hline & Inmigrantes & $\%$ & Españoles & $\%$ & Totales & $\%$ \\
\hline Hombre & $\mathbf{8 5}$ & $68,55 \%$ & 238 & $75,32 \%$ & 323 & $73,41 \%$ \\
\hline Mujer & 39 & $31,45 \%$ & 78 & $24,68 \%$ & 117 & $26,59 \%$ \\
\hline Total & 124 & $100,00 \%$ & 316 & $100,00 \%$ & 440 & $100,00 \%$ \\
\hline
\end{tabular}

A.T. EN ETT'S SEGUN GENERO Y NACIONALIDAD \% HORIZONTAL

\begin{tabular}{|l|c|c|c|c|c|c|}
\hline Género & \multicolumn{6}{|c|}{} \\
\hline & Inmigrantes & $\%$ & Españoles & $\%$ & Totales & $\%$ \\
\hline Hombre & 85 & $26,32 \%$ & 238 & $73,68 \%$ & 323 & $100,00 \%$ \\
\hline Mujer & 39 & $33,33 \%$ & 78 & $66,67 \%$ & 117 & $100,00 \%$ \\
\hline
\end{tabular}

Tablas $9 a$ y $9 b$. 


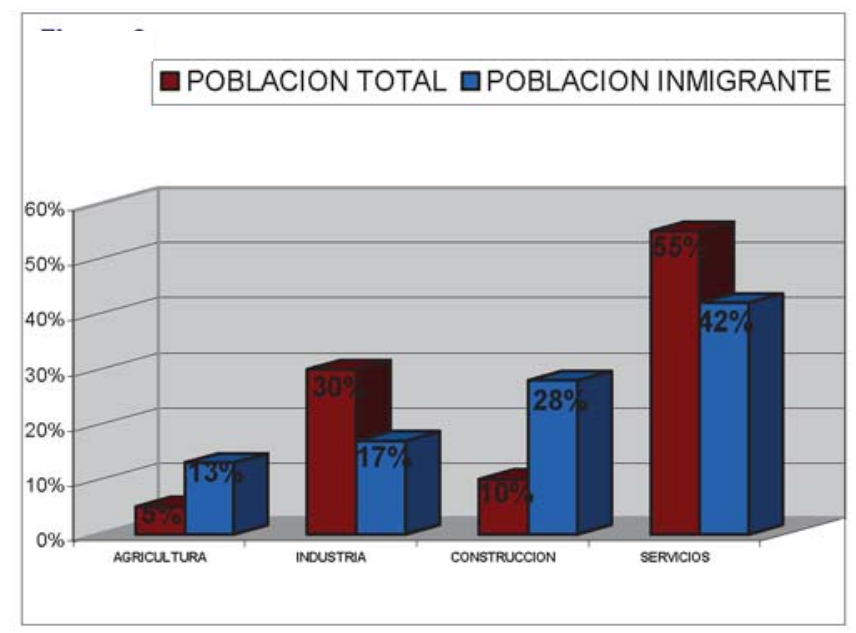

Figura 8

Por otra parte de los 22111 afiliados extranjeros el $88 \%$ lo está en el régimen general (de estos un $47 \%$ trabaja en el sector Servicios, un $31 \%$ en la Construcción y un 20\% en Industria), 210 son trabajadores autónomos con contingencias profesionales protegidas (de estos el 62\% ocupados en la Construcción) y 2500 trabajadores están encuadrados en el régimen agrario. (Tabla 10).

Para encuadrar estos datos parece interesante comparar los indicadores de siniestralidad de Navarra con el conjunto de España.

Podemos decir que desde el año 2002 los Índices de incidencia globales de AT de Navarra presentan valores inferiores a los del conjunto del estado. Según este indicador en 2006, Navarra se encuentra posicionada en el puesto $\mathrm{n}^{\circ} 12$ (de las 19 CCAA).

El Índice de incidencia (por mil trabajadores) de AT graves en Navarra en el año 2006 está por debajo del de España y solo el Índice de incidencia de AT mortales supera ligeramente al del estado, situándonos en el puesto $\mathrm{n}^{0} 6$. Los índices sectoriales de Navarra son inferiores a los de España en los tres sectores, excepto en agricultura (desde el año 2003).

Igualmente, excepto en agricultura y otras actividades empresariales, las actividades que presentan mayores porcentajes de AT en población inmigrante mantienen en el año 2006 índices de incidencia en Navarra inferiores a los del conjunto del estado.
Teniendo en cuenta un $\mathrm{n}^{\mathrm{o}}$ de población afiliada mayor de 500 trabajadores destacan en la población extranjera elevados índices de incidencia de AT en: Industrias manufactureras; Construcción; y Otras actividades sociales, servicios personales y en población nacional en Construcción; Industrias manufactureras; y Transporte, almacén y comunicaciones.

$\mathrm{Al}$ analizar los índices de incidencia de A.T. por sección de actividad observamos que dichos índices son superiores en el colectivo de extranjeros al compararlos con los índices en población total incluso en aquellas actividades menos representadas. Así en algunas secciones de actividad como en Industrias manufactureras; Comercio, reparación de vehículos a motor; Actividades inmobiliarias, alquileres de servicios; Otras actividades sociales, servicios personales estos índices se duplican, e incluso se triplican en otras como Actividades sanitarias y veterinarias, servicios sociales. (Tabla 11).

En la población inmigrante tanto los índices de incidencia globales como los diferentes índices de incidencia según gravedad se duplican con respecto a la población nacional. La probabilidad de sufrir un accidente grave o mortal en este colectivo es entre un $40-50 \%$ más elevada.

Índices de incidencia de AT en trabajadores extranjeros afiliados al régimen general de la SS según países de origen. 


\section{TRABAJADORES EXTRANJEROS AFILIADOS AL REGIMEN GENERAL, RÉGIMEN ESPECIAL AGRARIO Y TRABAJADORES EXTRANJEROS AUTÓNOMOS QUE HAN OPTADO POR LA COBERTURA DE LAS CONTINGENCIAS DE AT. Y EP., POR SECTORES Y SECCIONES ECONÓMICOS}

\section{NAVARRA AÑO 2006}

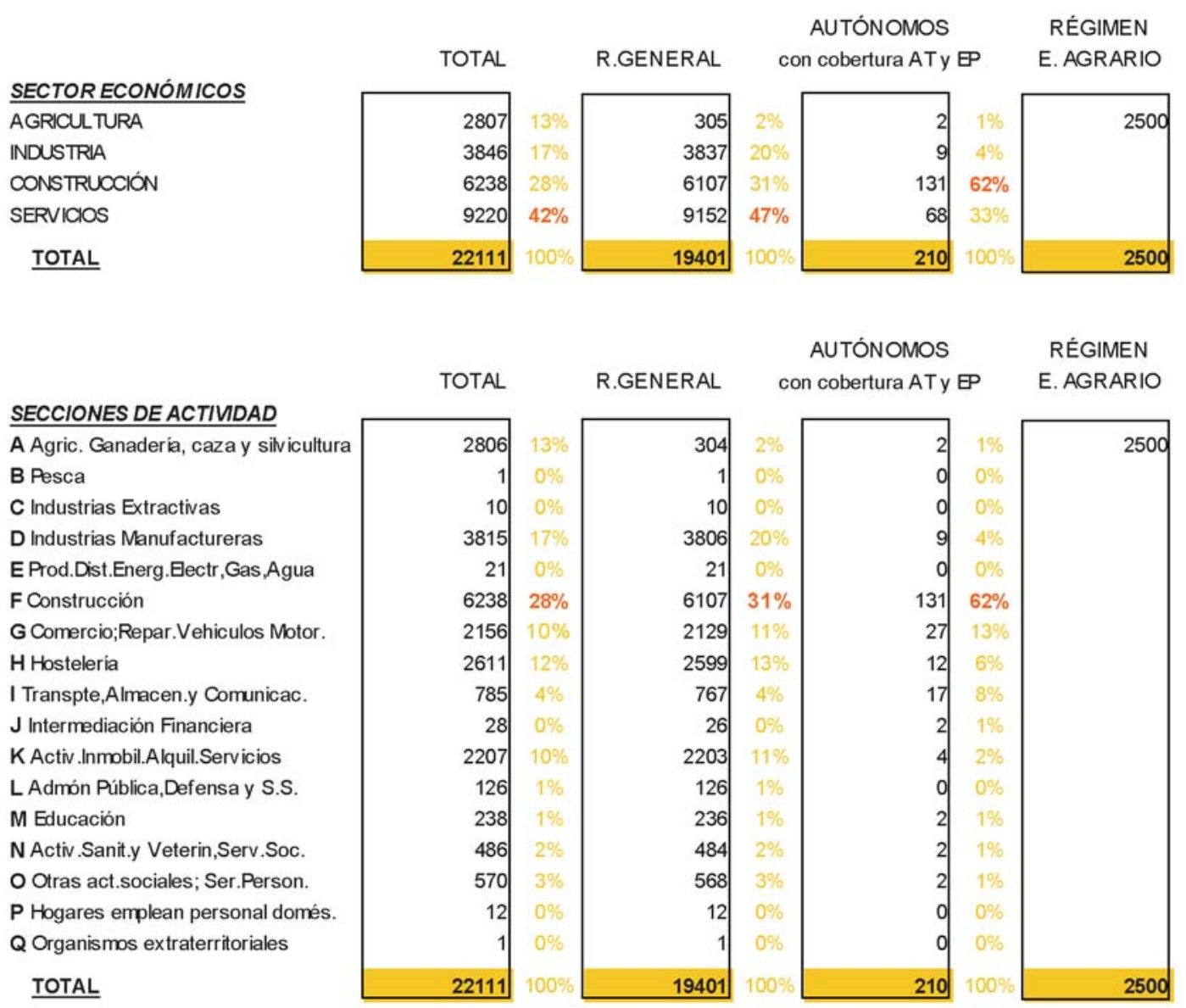

Tabla 10

La distribución porcentual de trabajadores afiliados al régimen general de la SS y los AT en trabajadores extranjeros según países de origen se representan gráficamente en las siguientes figuras (Figuras 9 y 10)

Los índices de incidencia de AT en población extranjera se han analizado desde diferentes perspectivas. El índice de incidencia global es de 131,5 por 1000 trabajadores, siendo inferior en los países de la unión europea (119 por mil trabajadores) en relación al resto de países no UE. (Tabla 12)
Superan la media, los altos índices de incidencia de AT en trabajadores nacidos en el Magreb y Europa Occidental (debido a la alta incidencia de AT en trabajadores de origen portugués) y África. Los valores más bajos los presentan trabajadores provenientes de Europa del Este y Norteamérica. (Tabla 13)

Si analizamos los índices por países (teniendo en cuenta aquellos con un alto porcentaje de AT en sus trabajadores) se objetivan altos índices, muy superiores a la media en Marruecos, Argelia y Portugal. 


\section{ACCIDENTES DE TRABAJO CON BAJA EN JORNADA DE TRABAJO SEGÚN NACIONALIDAD POR SECCIÓN DE ACTIVIDAD NAVARRA 2006}

\begin{tabular}{|l|}
\hline SECCIÓN DE ACTIVIDAD \\
\hline A Agricultura,Ganad.,Caza y Silv. ( ${ }^{*}$ ) \\
\hline B Pesca \\
\hline C Industrias Extractivas \\
\hline D Industrias Manufactureras \\
\hline E Prod.Dist.Energ.Eléctr,Gas,Agua \\
\hline F Construcción \\
\hline G Comercio;Repar.Vehículos Motor. \\
\hline H Hostelería \\
\hline I Transpte,Almacen.y Comunicac. \\
\hline J Intermediación Financiera \\
\hline K Activ.Inmobil.Alquil.Servicios \\
\hline L Admón Pública,Defensa y S.S. \\
\hline M Educación \\
\hline N Activ.Sanit.y Veterin,Serv.Soc. \\
\hline O Otras act.sociales; Ser.Person. \\
\hline P Hogares emplean personal domés. \\
\hline Q Organismos Extraterritoriales \\
\hline TOTAL (**) \\
\hline
\end{tabular}

\begin{tabular}{|c|c|c|}
\hline \multicolumn{3}{|c|}{ Extranjero } \\
\hline $\begin{array}{c}\text { AT. Con } \\
\text { baja en } \\
\text { jornada } T^{\circ}\end{array}$ & Población & $\begin{array}{l}\text { Indice de } \\
\text { Incidencia * } \\
1000 \text { trab. }\end{array}$ \\
\hline 133 & 2.806 & 47,4 \\
\hline 0 & 1 & 0,0 \\
\hline 3 & 10 & 297,5 \\
\hline 674 & 3.815 & 176,7 \\
\hline 3 & 21 & 142,9 \\
\hline 1.041 & 6.238 & 166,9 \\
\hline 175 & 2.156 & 81,2 \\
\hline 122 & 2.611 & 46,7 \\
\hline 74 & 785 & 94,3 \\
\hline 0 & 28 & 0,0 \\
\hline 216 & 2.207 & 97,9 \\
\hline 18 & 126 & 143,1 \\
\hline 3 & 238 & 12,6 \\
\hline 27 & 486 & 55,6 \\
\hline 63 & 570 & 110,6 \\
\hline 0 & 12 & 0,0 \\
\hline 0 & 1 & 0,0 \\
\hline 2.552 & 22.111 & 115,4 \\
\hline
\end{tabular}

\begin{tabular}{|r|r|r|}
\hline \multicolumn{3}{|c|}{ TOTAL 2006 } \\
\hline $\begin{array}{c}\text { AT. Con } \\
\text { baja en } \\
\text { jornada To }\end{array}$ & Población & $\begin{array}{c}\text { Indice de } \\
\text { Incidencia * } \\
\text { 1000 trab. }\end{array}$ \\
\hline 391 & 11.415 & 34,3 \\
\hline 2 & 6 & 311,7 \\
\hline 52 & 485 & 107,3 \\
\hline 5.034 & 63.834 & 78,9 \\
\hline 84 & 1.620 & 51,9 \\
\hline 2.964 & 23.792 & 124,6 \\
\hline 1.233 & 30.478 & 40,5 \\
\hline 392 & 10.750 & 36,5 \\
\hline 531 & 9.225 & 57,6 \\
\hline 13 & 4.780 & 2,7 \\
\hline 960 & 21.952 & 43,7 \\
\hline 263 & 8.100 & 32,5 \\
\hline 75 & 11.277 & 6,7 \\
\hline 359 & 18.562 & 19,3 \\
\hline 382 & 8.379 & 45,6 \\
\hline 3 & 347 & 8,6 \\
\hline 1 & 12 & 86,3 \\
\hline 12.739 & 225.013 & $\mathbf{5 6 , 6}$ \\
\hline & & \\
\hline
\end{tabular}

(") Incluye Régimen Especial Agrario Cuenta Propia y Cuenta Ajena

("win) Incluye Régimen de Trabajadores Autónomos que han optado por la cobertura de las contingencias de AT. y EP.

\section{Tabla 11}

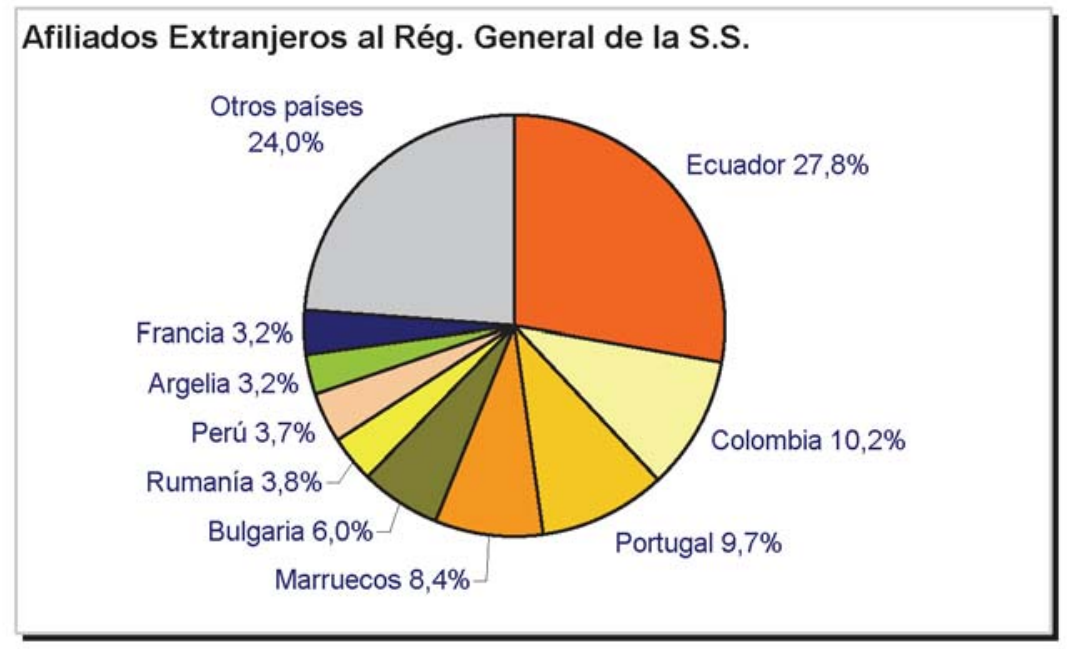

Figura 9 


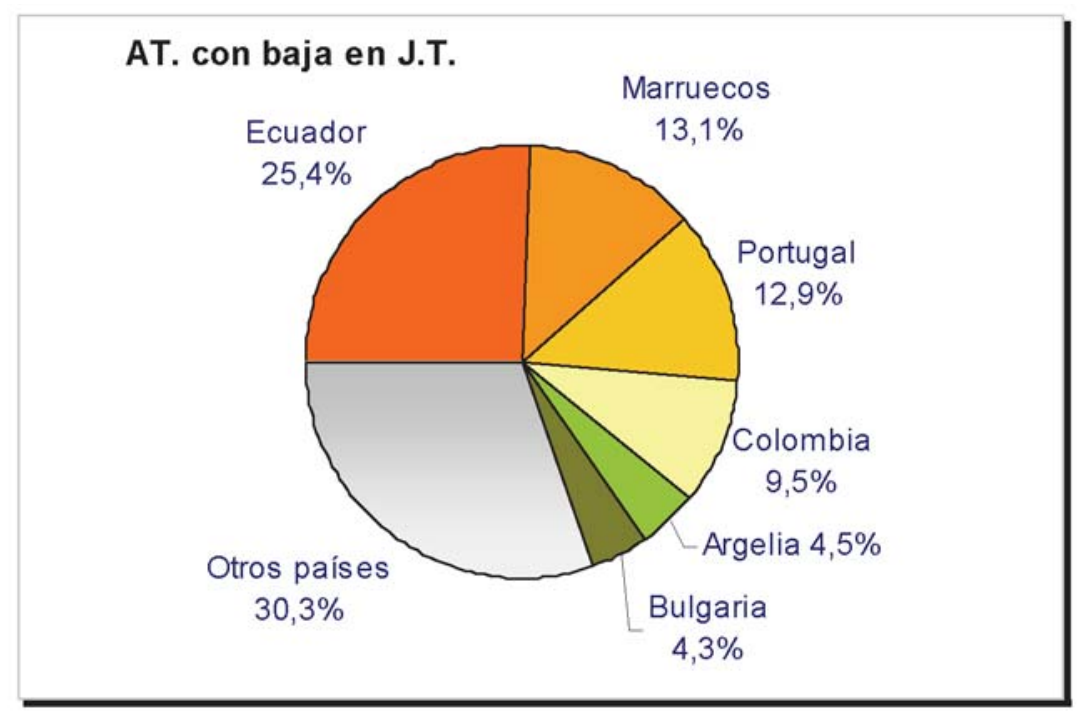

Figura 10

INDICES DE INCIDENCIA DE ACCIDENTES DE TRABAJO CON BAJA EN JORNADA DE TRABAJO EN TRABAJADORES EXTRANJEROS AFILIADOS AL REGIMEN GENERAL DE LA SEGURIDAD SOCIAL

NAVARRA AÑO 2006

\begin{tabular}{|l|c|c|c|}
\hline \multirow{2}{*}{$\begin{array}{l}\text { AT. CON BAJA EN JORNADA DE } \\
\text { TRABAJO }\end{array}$} & \multicolumn{3}{|c|}{ RÉGIMEN GENERAL } \\
\cline { 2 - 4 } & $\begin{array}{c}\text { A.T. con baja en } \\
\text { J.T. }\end{array}$ & $\begin{array}{c}\text { Trabajadores } \\
\text { Extranjeros } \\
\text { Afiliados }\end{array}$ & $\begin{array}{c}\text { I. Incidencia por } \\
1000 \text { trab }\end{array}$ \\
\hline Paises de la Unión Europea & 630 & 5294 & 119,0 \\
Resto Paises & 1922 & 14107 & 136,2 \\
Total Extranjeros & 2552 & 19401 & 131,5 \\
\hline
\end{tabular}

Tabla 12

\begin{tabular}{|l|r|r|r|}
\hline & \multicolumn{3}{|c|}{ RÉGIMEN GENERAL } \\
\cline { 2 - 4 } & $\begin{array}{c}\text { A.T. con baja en } \\
\text { J.T. }\end{array}$ & $\begin{array}{c}\text { Trabajadores } \\
\text { Extranjeros } \\
\text { Afiliados }\end{array}$ & $\begin{array}{c}\text { Indice Incidencia } \\
\text { por 1000 trab }\end{array}$ \\
\hline EUROPA ESTE & 267 & 2900 & 92,1 \\
\hline EUROPA OESTE & 421 & 3128 & 134,6 \\
\hline ASIA & 23 & 305 & 75,5 \\
\hline AFRICA & 117 & 910 & 128,6 \\
\hline MAGREB & 455 & 2288 & 198,8 \\
\hline AMERICA NORTE & 3 & 52 & 57,8 \\
\hline CENTRO + SUD AMERICA & 1157 & 9798 & 118,1 \\
\hline OCEANIA & 1 & 4 & 285,7 \\
\hline NC & 108 & 18 & \\
\hline TOTAL & $\mathbf{2 5 5 2}$ & $\mathbf{1 9 4 0 1}$ & $\mathbf{1 3 1 , 5}$ \\
\hline
\end{tabular}

Tabla 13 


\begin{tabular}{lrrr} 
País & $\underline{\text { AT }}$ & Trab. Ext. & I.I. por mil \\
Ecuador & 649 & 5388 & 120,5 \\
Marruecos & 334 & 1634 & 204,4 \\
Portugal & 328 & 1891 & 173,5 \\
Colombia & 242 & 1970 & 122,8 \\
Argelia & 115 & 620 & 185,5 \\
Bulgaria & 111 & 1166 & 95,2 \\
Otros países & 773 & 6732 & 114,8 \\
\hline TOTAL & 2552 & 19401 & 131,5 \\
\hline \hline
\end{tabular}

Tabla 14

Otros países como Ecuador y Colombia presentan valores por debajo de la media. (Tabla 14)

\section{CONCLUSIONES Y DISCUSIÓN}

1.- Se observa un exceso de siniestralidad en este colectivo. Para un $\mathbf{9 , 8 \%}$ de trabajadores extranjeros afiliados, estos sufren el $20 \%$ de los AT. Las mujeres extranjeras se accidentan casi 4 puntos menos en porcentaje relativo que las nacionales.

2.- Según gravedad, el perfil de distribución es similar en ambas poblaciones. Los trabajadores extranjeros sufrieron 1 de cada 5 accidentes graves y 1 de cada 6 mortales.

3.- Existe mayor proporción de AT en este colectivo en los grupos de edad más jóvenes.

Una característica ya conocida de la población trabajadora inmigrante es que poseen una media de edad más baja. Este dato podría justificar la mayor proporción de AT en los grupos de edad más jóvenes en este colectivo que se observa en nuestro análisis. En este sentido hay datos que relacionan mayor gravedad de accidentes, mayor mortalidad y menor incidencia con el mayor envejecimiento de la población trabajadora ${ }^{4}$.

4.-Por sectores económicos: una tercera parte de los accidentes en Agricultura y Construcción corresponden a trabajadores inmigrantes. Su distribución porcentual es reflejo de la diferente inserción laboral atendiendo al sexo y ocupación sectorial de este colectivo, duplicando los porcentajes en los sectores agrícolas y construcción en comparación con la población de acogida. En población extranjera la proporción de hombres que se accidentan es superior en todos los sectores productivos, excepto en Servicios.

Asistimos a una progresiva feminización de los flujos migratorios -según datos del padrón de habitantes en Navarra a 1de Enero de 2006, el 46\% de los emigrantes son mujeres- producto tanto de los esfuerzos de las mujeres por ganar autonomía como del aumento de la demanda del sector servicios, donde muchas mujeres se insertan laboralmente ${ }^{5}$. Sin embargo la presencia de mujeres inmigrantes varía según el lugar de procedencia, siendo mayor en las nacionalidades latinoamericanas y menor en la población africana, antiguos países de Europa del Este y asiáticos ${ }^{6}$.

La inserción laboral de este colectivo presenta algunas características específicas. Los trabajadores inmigrantes trabajan con mayor frecuencia en algunas ramas de actividad: los hombres en construcción y agricultura y en el caso de las mujeres en servicio doméstico y hostelería, actividades que han sido progresivamente abandonadas por los trabajadores de origen nacional debido a la flexibilidad y desregulación que las caracterizan ${ }^{7}$. Asimismo, estos sectores presentan las mayores tasas de contratación temporal, evidenciando la extensión de la precariedad entre este colectivo.

5.- La forma de producción, descripción y localización de las lesiones y el agente material 
responsable presentan una distribución superponible en ambos colectivos.

6.-Cerca del $80 \%$ de los AT en población inmigrante acontece en puestos de baja cualificación o no cualificados y casi tres cuartas partes de los trabajadores inmigrantes accidentados llevaban menos de un año de antigüedad en su trabajo.

El porcentaje relativo los AT notificados por ETT en inmigrantes superan a los notificados en población nacional y mientras que casi el $75 \%$ se dan en varones, una tercera parte corresponden a población trabajadora extranjera. Además mientras el peso relativo de los AT ocurridos en mujeres extranjeras con esta modalidad de contrato supera al de españolas, en los varones ocurre lo contrario.

La precariedad laboral es un fenómeno emergente del mercado de trabajo actual, producto de las trasformaciones que se suceden a nivel mundial, cuyo origen proviene del proceso de internacionalización de la producción industrial, la desregulación laboral y los cambios en la organización del trabajo. Como consecuencia de estas trasformaciones se ha extendido la flexibilidad productiva y consecuentemente las empresas han desarrollado estrategias como la externalización, la subcontratación y el empleo eventual ${ }^{8}$. La flexibilidad laboral ha fomentado el nacimiento de formas de empleo atípicas, que han ido reemplazando el empleo estándar, permanente, a tiempo completo por empleos inseguros, inestables, de bajo nivel salarial y peores condiciones de trabajo ${ }^{9,10}$. No existe una definición consensuada del concepto precariedad, que con frecuencia se ha equiparado al de temporalidad. Sin embargo varios autores han demostrado como la temporalidad es tan sólo una de las dimensiones de ésta ${ }^{11,12}$ .Por ejemplo, la desclasificación, la vulnerabilidad ante el trato discriminatorio o arbitrario, o la ausencia de derechos sociales derivados del contrato laboral pueden ser otros rasgos que la definan. Esta situación descrita afecta en mayor grado a la población extranjera, quien, independientemente de su nivel de formación y experiencia profesional, es seleccionada para los trabajos menos cualificados, de menor contenido, menos valorados y pagados y en peores condiciones de empleo. Los trabajadores inmigrantes al insertarse en el mercado laboral representan una gran proporción de trabajadores temporales y un extenso número de trabajadores en situación irregular ${ }^{10}$. Las condiciones de trabajo de la población ocupada inmigrante implican, en muchos casos, jornadas reducidas o muy largas y con frecuencia menor antigüedad en el empleo producto de una mayor temporalidad y mayor índice de rotación.

Los índices de incidencia de AT en Navarra en el periodo 1997-2002 se triplican en la población trabajadora con contrato temporal frente a los trabajadores con contrato indefinido. De igual manera los grupos de profesiones con menor nivel de cualificación mantiene unos índices de incidencia muy superiores al índice medio global ${ }^{13}$. En nuestro análisis un $80 \%$ de los accidentes en población inmigrante ocurren en puestos de baja cualificación o no cualificados, frente al $62 \%$ en población trabajadora nacional. Los mayores porcentajes de AT en "trabajadores no cualificados" ocurrieron en aquellos procedentes de África subsahariana y el Magreb que coinciden con zonas geográficas de origen con altos índices de incidencia de AT.

Si bien se han publicado numerosos trabajos que analizan la situación de la población inmigrante ${ }^{14,15}$, existe poca información sobre los aspectos relacionados con el impacto en la salud que puede tener un medio laboral caracterizado por alto nivel de precariedad.

Los estudios científicos que analizan esta relación se centran sobre todo en el colectivo de trabajadores con contratos temporales., demostrando cómo la salud de éstos tiende a ser peor que la de los trabajadores con contratos estables .Entre los trabajadores con contratos temporales existe un mayor deterioro de la salud psíquica, desmotivación e insatisfacción laboral y un mayor riesgo de padecer accidentes laborales ${ }^{16,17,18,19}$. La relación entre el trabajo informal y las consecuencias negativas para la salud ha permitido constatar la existencia de un mayor nivel de ansiedad o mostrar un pesimismo sobre el futuro. Los trabajadores informales tienen un estatus inferior y menos control sobre su salario y condiciones de trabajo. A su vez, la incertidumbre sobre su futuro laboral, sumada a niveles salariales más bajos y a la falta de beneficios sociales pueden incrementar el estrés y los trastornos mentales menores y como consecuencia aumentar riesgo de accidentes laborales $\mathrm{s}^{20,21,22}$. 
Por otra parte, existe evidencia de que los inmigrantes tienen mayor predisposición a padecer trastornos mentales, fruto de la experiencia de la inmigración. El proceso migratorio conlleva la pérdida de la red social de apoyo, el distanciamiento debido a la lengua y un cambio en el estatus social de la persona. En esta situación resulta fundamental el papel que juega su situación laboral en el malestar que muchos padecen y en la peor salud autopercibida que muestran frente a la población autóctona ${ }^{23}$. En general los trabajadores inmigrantes desempleados experimentaban más síntomas físicos y mentales crónicos atribuidos a su situación laboral y consideraban su salud menos satisfactoria ${ }^{22,24,25}$.

La Encuesta Nacional de Condiciones de Trabajo del año 2005 demuestra que la demanda de asistencia sanitaria es superior en trabajadores de nacionalidad no española e igualmente es mayor la solicitud de asistencia sanitaria por dolencias relacionadas con el trabajo. Este análisis reveló que entre los motivos de consulta más frecuentes en este colectivo en comparación con los trabajadores españoles destacaban la depresión y la fatiga crónica ${ }^{26}$.

7.-En nuestro estudio observamos que los Índices de incidencia de AT por sección de actividad son superiores en el colectivo de extranjeros al compararlos con los índices en población total, incluso en aquellas actividades menos representadas. En población inmigrante tanto los índices de incidencia globales como los diferentes índices según gravedad se duplican respecto de la población nacional .Estos datos coinciden con los presentados por el estudio de Bollini \& Siem en 1995. Estos autores concluyen que las tasas de lesiones ocupacionales en los trabajadores inmigrantes en países de nuestro entorno europeo son dos veces más altas que en los trabajadores nativos ${ }^{27}$.

En nuestro trabajo el índice de incidencia global de AT es de 131,5 por 1000 trabajadores, siendo inferior para los sucesos ocurridos en trabajadores provenientes de la UE-25 (119 por mil). Superan la media los índices en trabajadores nacidos en el Magreb y Europa Occidentaldebido a la alta incidencia de AT en trabajadores de origen portugués- y África, destacando índices muy elevados en los trabajadores de Marruecos, Argelia y Portugal.
El grado de información sobre la relación entre inmigración y siniestralidad es en general escaso y prácticamente inexistente en España. Un reciente estudio en nuestro país destaca las diferencias en las lesiones por accidente de trabajo tanto mortales como no mortales entre los trabajadores inmigrantes y los autóctonos .El riesgo elevado se mantiene en todos los grupos de edad, observándose mayor riesgo en las mujeres y los trabajadores de más de 55 $\operatorname{años}^{28}$.

Otros estudios llevados a cabo en USA, usando datos administrativos encontraron que los AT mortales se incrementaban entre los trabajadores extranjeros mientras que disminuían entre los autóctonos ${ }^{29}$, y que los inmigrantes hispanos ${ }^{30,31}$ y otros grupos minoritarios presentaban tasas más altas de sucesos fatales. En Australia las tasas medias globales de AT mortales eran similares entre nativos y trabajadores extranjeros, sin embargo éstas se eran más elevadas en los trabajadores extranjeros en ciertas ocupaciones y entre los inmigrantes recién llegados de países de habla no inglesa ${ }^{32}$.

Los resultados referidos a lesiones no mortales son menos consistentes. Diversos estudios muestran en general un ligero aumento de los índices de accidentes no fatales entre los trabajadores extranjeros y un mayor número de días de ausencia al trabajo, sugestivo de lesiones mas graves ${ }^{27,33,34}$. En contraste, en un estudio longitudinal en USA, los autores no encontraron diferencias para los trabajadores hispanos en relación a lesiones profesionales, aunque los hombres reportaban mayor número de días de trabajo perdidos ${ }^{35}$.

Los resultados de estos estudios nos llevan a cuestionarnos sobre cuales pueden ser las causas que subyacen en las diferencias observadas.

Se sugiere que los trabajadores inmigrantes se concentran en trabajos más arriesgados o son asignados a tareas más peligrosas en esos trabajos ${ }^{36}$. Datos de EEUU indican que agricultura, construcción, servicios y determinadas actividades industriales, conocidos por sus mayores riesgos presentan altas concentraciones de trabajadores inmigrantes ${ }^{37}$. Similares patrones de inserción laboral han sido descritos en países europeos de nuestro entorno, con trabajadores inmigrantes concentrados en trabajos 
no especializados y poco cualificados ${ }^{24,38}$.Igualmente nuestros datos confirman la diferente distribución laboral por sectores productivos del colectivo de extranjeros en relación a la población total. Así, los sectores de mayor inserción de la población extranjera son Servicios (42\%)-destacando actividades como hostelería, act. inmobiliarias, alquileres, servicios- y Construcción (28\%). Sin embargo, se ha comunicado que las diferencias en las tasas de siniestralidad permanecen incluso analizando las mismas ocupaciones, lo que sugiere otros factores involucrados además de la ocupación $27,29,31$.

Diversos autores han sugerido barreras idiomáticas como posible factor, influyendo tanto en la formación en seguridad como en la comunicación en el trabajo. Refieren que estas dificultades tiene que ver con la falta de comprensión de la formación en seguridad, el idioma en la que se realiza y la duración de la misma, que suele ser menor en estos trabajadores $^{34,36,39}$.

Otros estudios han mostrado alto riesgo en los trabajadores recién llegados. Así Corvalan CF \& col $(1994)^{32}$ describen que las tasas de accidentes fatales se aproximan a las de la población nativa después de cinco o más años de residencia en Australia, sugiriendo que podría estar relacionado con el proceso de adaptación y adquisición del idioma.

Brunette MJ, (2004) ${ }^{40}$ defiende que la formación en seguridad y salud debería contemplar no solo aspectos relacionados con el entorno laboral, sino tener en cuenta aspectos económicos, sociales y culturales.

Resulta, pues, necesario adentrarse y profundizar en el conocimiento de cuales pueden ser, si existen de manera particularizada, los mecanismos intermedios en la generación de accidentes laborales en el colectivo extranjero.

En este sentido un análisis cualitativo de la mortalidad por AT en España 2003-2004 puede aportar algún dato al respecto. Este documento publicado por el INSHT en el 2007, analiza en uno de sus apartados las causas de AT por nacionalidad en una muestra de trabajadores extranjeros fallecidos que representan el $9.6 \%$ del total.
Se estudian las causas específicas y clasificadas en bloques, encontrándose diferencias significativas a favor del colectivo extranjero en deficiencias de protección y señalización y en las de organización del trabajo y tareas ("instrucciones inexistentes, confusas o insuficientes" y "formación-información inadecuada o inexistente sobre riesgos y medidas preventivas"), actividades consideradas de especial trascendencia en trabajadores de otro origen con lenguajes y probablemente métodos de trabajo diferentes ${ }^{41}$.

8.-Una de las limitaciones de nuestro análisis es que no aborda un aspecto importante que caracteriza a este colectivo como es la situación de irregularidad y su inserción laboral en la economía sumergida. Se estima que este sector representa entre el $16 \%$ y el $22 \%$ del PIB español ${ }^{42}$. El trabajo irregular no sólo dificulta su integración y estabilidad, sino que plantea problemas en la prevención de riesgos laborales y los expone a la marginación dentro de la sociedad de acogida. La escasa información sobre las características de los trabajadores inmigrantes en situación irregular revela la necesidad de estudios específicos que generen información primaria sobre su situación laboral: características de estos trabajadores, sectores productivos de inserción, tiempo que mantienen su economía informal o sus condiciones de trabajo.

Los registros oficiales de siniestralidad laboral no contemplan los accidentes de trabajo que padecen los trabajadores inmigrantes en situación de irregularidad. Las lesiones y enfermedades en estos grupos más vulnerables probablemente no son notificados y los problemas de salud relacionados con el trabajo no son clasificados como tales. Una encuesta domiciliaria realizada en trabajadores inmigrantes en Massachussets en EEUU comparaba los casos de lesiones y enfermedades comunicados con los casos registrados a través de indemnizaciones a los trabajadores y registros hospitalarios ${ }^{43}$. Los resultados revelan que las fuentes de datos no eran completas y que la encuesta domiciliaria detectaba casos claramente ausentes en los registros oficiales. Otros estudios apuntan la utilidad de monitorizar la siniestralidad laboral en estos colectivos a través de datos asistenciales obtenidos en clínicas y en salas hospitalarias de urgencia ${ }^{44}$. 


\section{J. FERNÁNDEZ BARAIBAR, J. R. AYESTARÁN RUIZ BAZÁN}

Esta invisibilidad en la situación de los trabajadores inmigrantes tiene un profundo significado y no solo individualmente. Sus efectos tienen una más extensa repercusión en el entorno laboral, familiar y comunitario .Las conexiones entre el impacto individual y social está mediatizado por otros factores como el tipo de trabajo y contrato, el tipo y severidad de las lesiones, las características sociodemográficas, situación económica, la duración de la enfermedad o discapacidad, el tiempo de residencia, la situación de regularidad o el acceso a los cuidados de salud ${ }^{45}$.

Algunos estudios describen como las reformas estructurales, económicas, legales y políticas llevadas a cabo por los gobiernos de algunos países podrían dificultar la denuncia y el conocimiento de pobres condiciones de trabajo y desalentar la notificación de las lesiones laborales e incluso podrían suponer barreras administrativas para el acceso a las indemnizaciones y a los cuidados de salud por para estos colectivos. Estos aspectos, relacionados con la notificación y vigilancia, han sido utilizados como indicadores para monitorizar la salud ocupacional ${ }^{46}$ $\mathrm{y}$ algunos investigadores proponen una interpretación en términos de reducción de derechos sociales ${ }^{27,47}$.

\section{BIBLIOGRAFIA}

1.-López de Lera D, Izquierdo Escribano A.(2004).Inmigración y población: incidencia de la población extranjera en el crecimiento de la población en Navarra."El impacto de la inmigración en una sociedad que se transforma". Gobierno de Navarra. Departamento de Bienestar Social, Deporte y Juventud.

2.-Laparra Navarro M, García de Eulate Jiménez JR, Andueza Imirizaldu I, Gónzalez Eransus R. (2004) Impacto de la inmigración en el mercado laboral. ."El impacto de la inmigración en una sociedad que se transforma". Gobierno de Navarra. Departamento de Bienestar Social, Deporte y Juventud.
9.-El estudio y la investigación de la situación laboral de los inmigrantes debe ser una prioridad desde el punto de vista de las políticas sociales, en general, y de la salud pública en particular. La evidencia científica indica que las clases sociales más desfavorecidas disponen de menos recursos socio-económicos, menos poder de decisión, peor atención sanitaria y están más expuestos a factores de riesgo que pueden impactar negativamente en su salud.

Al mismo tiempo deberían apoyarse y fomentarse más estudios a través de los cuales conocer las opiniones y percepciones que permitan dar voz a los propios protagonistas, como son los estudios cualitativos. Las diferencias culturales e idiomáticas dificultan la comunicación con este colectivo y limitan las habilidades de los inmigrantes para acceder a la educación y a programas formativos y preventivos que podrían proteger y mejorar su salud. De esta manera, reconocer y detectar las dificultades a las que se enfrentan, deberían ser considerados igualmente temas prioritarios en la agenda de investigación en salud pública y políticas sociales.

3.-Cachón Rodríguez L. (1997).Segregación sectorial de los inmigrantes en el mercado de trabajo en España. Cuadernos de Relaciones Laborales $\mathrm{n}^{\circ} 10$.

4.-García Barreiro A, Gallego I, Maqueda J. (2005)."Siniestralidad laboral y envejecimiento de la población trabajadora". Rev SEMST.2005; 1:79-86.

5.-Colectivo Ioé.(1999). Inmigrantes, trabajadores, ciudadanos. Una visión de las migraciones desde España. Valencia: Universitat de Valencia,1999.

6.-Instituto Nacional de Estadística. (2006) Avance del Padrón Municipal al 1 de Enero de2005. Instituto nacional de Estadística; 2005 [citado 7 de mar 2006].Disponible en :htpp://www.ine.es. 
7.-Martínez Veiga U. (1997) La integración social de los inmigrantes extranjeros en España. Madrid: Trotta; 1997.

8.-Porthé V, Amable M, Benach J. (2007)" La precariedad laboral y la salud de los inmigrantes en España: ¿qué sabemos y qué deberiamos saber?”. Arch Prev Riesgos Labor 2007; 10(1):34-39.

9.-Amable M, Benach J.(2000) "La precariedad laboral ¿un nuevo problema de Salud Pública?”.Gac Sanit.2000;28:418-21.

10.-Rodgers G.(1992) El debate sobre el Trabajo precario en Europa Occidental. En Gerry y J Rodgers, editores.El trabajo precario en la regulación del mercado laboral. Madrid: Ministerio de Trabajo y Seguridad Social;1992.p191-6.

11.-Amable M, Benach J, González S(2001). “La precariedad laboral y su repercusión sobre la salud. Concepto y resultados preliminares de un estudio multimétodos". Arch Prev Riesgos Labor. 2001;4: 169-84

12.-Amable M. (2006). La precariedad laboral y su impacto en la salud. Un estudio de trabajadores asalariados en España. Barcelona: Universitat Pompeu Fabra; 2006.

13.-Ganuza Arbizu J, García López V, Lezáun Goñi M.(2005). Lesiones Profesionales en Navarra 2002.Accidentes de trabajo y Enfermedades profesionales. Instituto Navarro de Salud Laboral. Departamento de Salud. Gobierno de Navarra,2005.

14.-Izquierdo Escribano A, Carrasco Carpio C. (2003).Inmigración,mercado de trabajo y protección social en España. Madrid: Consejo Económico y Social.

15.-Martínez Veiga U.(2004) Trabajadores invisibles. Precariedad, rotación y pobreza de la inmigración en España .Madrid :Catarata.2004.

16.-Benavides FG, Delclos G. (2005).'Flexible employment and health inequalities". J Epidemiol. Community Health. 2005; 59: 719-20.

17.-Kivimäki M, Vathera J, Virtanen M, Elovainio M, Pentti J, Ferrie J.(2003) “Temporary employ- ment and risk of overall and cause-specific mortality”. Am J Epidemiol.2003;158: 663-8.

18.-Bohle P, Quinlan M, Kennedy D, Williamson A. (2004)." Working hours, work-life conflict and health in precarious and"permanent" employment". Rev Saude Publ. 2004;38:19-25.

19.-Bardasi E, Francesconi M.(2004)." The impact of atypical employment on individual wellbeing:evidence from a panel of British workers". Soc Sci Med.2004; 58: 1671-88.

20.-Benach J, Amable M, Muntaner C, Benavides FG.(2002)." The consequences of flexible work for health: are we looking at the right place?".J Epidemiol Community Health.2002; 56:405-6.

21.-Ludemir AB, Lewis G. (2003)."Informal work and common mental disorders". Soc Psytriachy Psychiatr Epidemiol.2003; 38:485-9.

22.-Akhavan S, Bildt CO, Franzén EC, Wamala S. (2004)"Health in relation to unemployement and sick leave among immigrants in Sweden from a gender perspective". J Immigr Health : 2004:6 (3); 103-18.

23.-Jansá JM, Odónez JI. (2005). Nous elements en salut i immigració. En: Borrell C, Benach J, editores . Evolució de les desigualtats en la salut en Catalunya. Barcelona: Mediterrània; 2005.p. 205-33.

24.-Elkeles T, Seifert W.(1996)."Inmigrants and Health: unemployement and health-risks of labour migrants in federal Republic of Germany,19841992”.Soc Sci Med.1996:43(7);1035-47.

25.-Rosmond R, Lapidus L, Björntorp P. (2003). "A cross-sectional study of self reported work conditions and psyquiatric health in native Swedes and immigrants". Occup Med. 1998;48(5):309-14.

26.-Almódovar Molina A, Nogareda Cuixart C, Fraile Cantalejo A y cols. Encuesta Nacional de Condiciones de Trabajo 2005.Madrid: Instituto Nacional de Seguridad e Higiene en el Trabajo. Ministerio de Trabajo y Asuntos Sociales; 2006.

27.-Bollini P, Siem H.(1995)."No real progress towards equity: health of migrants and ethnic 
minorities on the eve of year 2000". Soc Sci Med. 1995; 41(6):819-28.

28.-Ahonen E, Benavides FG. (2006)."Risk of fatal and non-fatal occupational injury in foreign workers in Spain". J Epidemiol Community Health.2006; 60: 424-6.

29.-Loh K, Richardson S. (2004). "Foreign-born workers: tends in fatal occupational injuries, 19962001”.Mon Labor Rev.2004;127 :42-53.

30.-Richardson DB, Loomis D, Bena J, Bailer AJ.(2004)." Fatal occupational injury rates in southern and non-southern States, by race and Hispanic ethnicity" .Am J Public Health.2004; 94(10):1756-61.

31.-Dong X, Platner JW.(2004).”Occupational fatalities of Hispanic construction workers from 1992-2000".Am J Ind Med. 2004;45:45-54.

32.-Corvalan CF, Driscoll TR, Harrison JE. (1994). "Role of migrant factors in work-related fatalities in Australia". Scand J Work Environ Health. 1994; 20:364-70.

33.-Carangan M, Tham KY, Seow E. (2004)."Work-related injury sustained by foreign workers in Singapore". Ann Acad Med Singapore. 2004; 33:209-13.

34.-Pransky G, Moshenberg D, Benjamin K, Portillo S, Thackrey JL, Hill-Fotouhi C.(2002). “Occupational risks and injuries in non-agricultural immigrant Latino worker". Am J Ind Med. 2002; 42:117-23.

35.-Strong LL, Zimmerman FJ.(2005)." Occupational injury and absence from work among African American, Hispanic, and non- Hispanic White workers in the National Longitudinal Survey of Youth". Am J Public Health. 2005 ;95(7):1226-32.

36.-Azaroff LS, Levenstein C, Wegman DH.(2005).'The occupational health of Southeast Asian in Lowell: a descriptive study". Int J Ocupp Environ Health.2004;10:47-54.

37.-McCaule LA(2005). "Immigrant workwers in the United States: recent trends, vulnerable populations, and challenges for occupational health". AAOHN J.2005; 53 (7):313-9.
38.-Capacci F, Carnevale F, Gazzano N. (2005)." The health of foreign workers in Italy" Int J Occup Environ Health.2005; 11:64-9.

39.-O'Connor T, Loomis D, Runyan C, Abboud dal Santo, Schulman M.(2005)" Adequacy of health and safety training among young Latino construction workers".J Occup Environ Med. 2005;47 (3):272-7.

40.-Brunette MJ. (2004). "Construction safety research in the United States: targeting the Hispanic workforce". Inj Prev.2004;10: 244-8.

41.-Grupo de trabajo del INSHT (2007). Análisis cualitativo de la mortalidad por Accidente de trabajo en España 2003-2004. Madrid: Instituto Nacional de Seguridad e Higiene en el Trabajo. Ministerio de Trabajo y Asuntos Sociales, 2007.

42.-Zaguirre Altuna A. (2004). Los procesos migratorios. Alternativas al discurso dominante. Madrid: Fundación alternativas; 2004.

43.-Azaroff LS, Levenstein C, Wegman DH. (2003). "Occupational health of Southeast Asian Immigrants in A US city: a comparison of data sources". Am J Public Health.2003;93(4):593-8.

44.-Earle-Richardson G, Jenkins PL, Slingerhead DT, Mason C, Miles M, May JJ. (2003). “Occupacional injury and illness among migrant and seasonal farmworkers in New York state and Pennsylvania,1997-1999: pilot study of new surveillance method". Am J Ind Med. 2003;44:37-45.

45.-Dembe AE.(2001)." The social consequences of occupational injuries and illnesses". Am J Ind Med.2001;40:403-17.

46.-Azaroff LS, Lax MB, Levenstein C, Wegman DH.(2004). "Wounding the messenger: the new economy makes occupational health indicators too good to be true". Int J Health Serv. 2004; 34(2):271-303.

47.-Ahonen EQ, Benavides FG, Benach J.(2007) "Immigrant populations, work and health-a systematic literature review". Scand J Work Environ Health. 2007; 33(2):96-104 